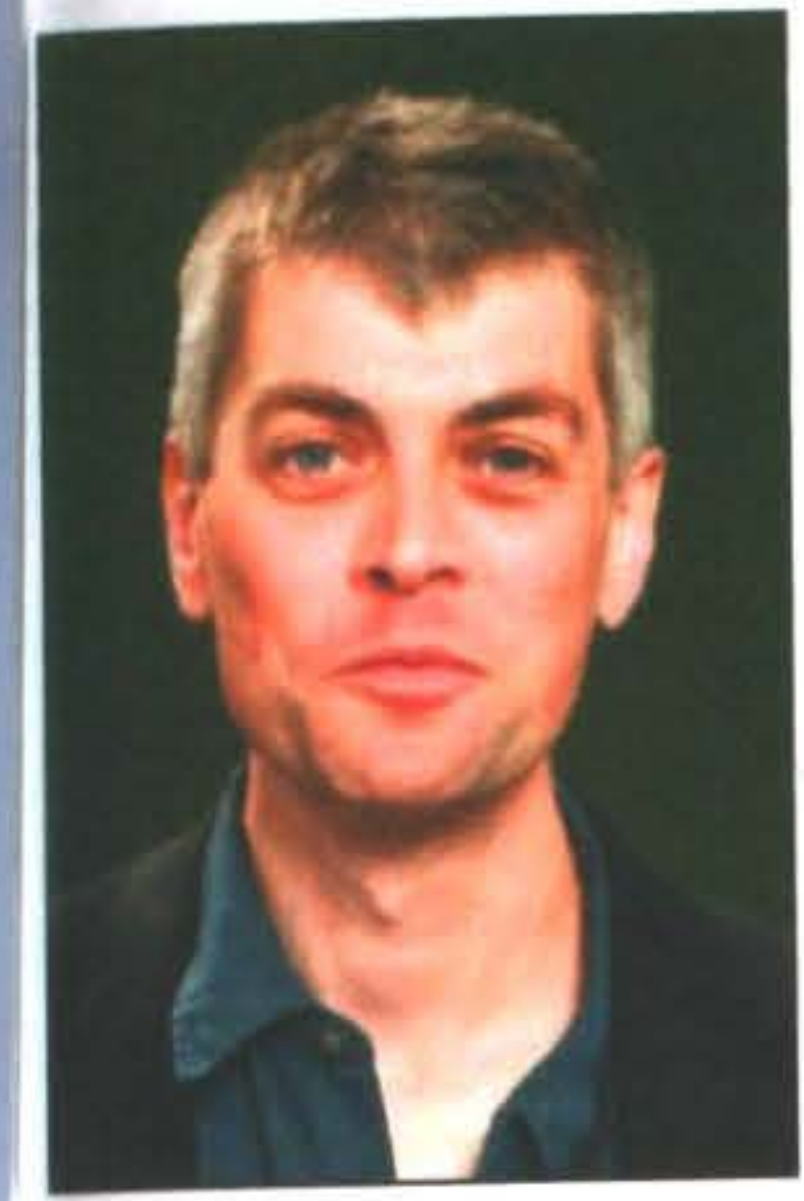

\title{
THE DAILY COMMUTE: \\ AN ANALYSIS OF THE GEOGRAPHY OF THE LABOUR MARKET USING 2006 CENSUS DATA
}

Martin Ralphs and Rosemary Goodyear

\author{
Statistics New Zealand
}

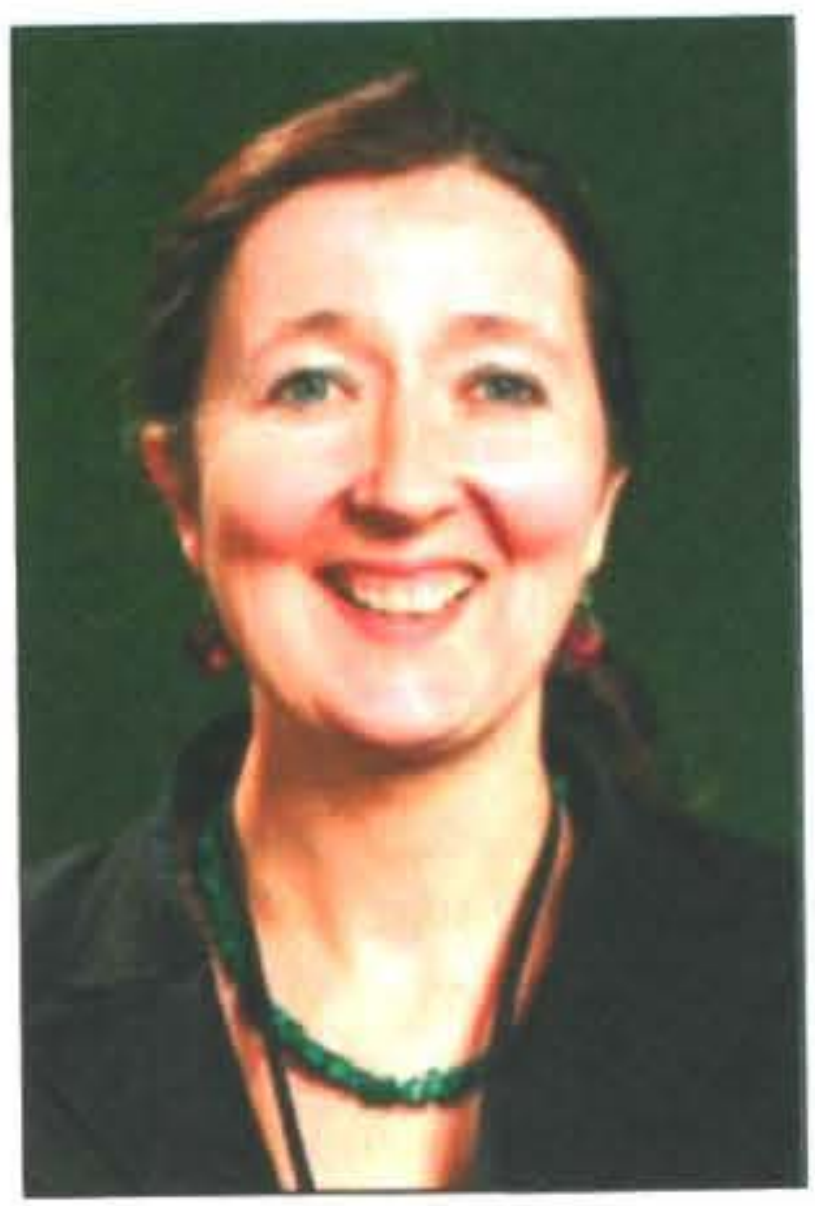

Abstract

This paper explores the major commuting areas within New Zealand and how commuting patterns have evolved between 1996 and 2006. It focuses primarily on the new insights that mapping and visualisation methods can bring to the analysis and understanding of complex flow data. In particular, we discuss some approaches to delineating labour market areas based on commuter inflow statistics and demonstrate the advantages that spider flow maps bring to the visualisation and understanding of commuting flows between areas. Spider flow maps are based on origin-destination information from the 2006 Census, but the paper also includes an historical perspective, examining changes in the number and proportion of people commuting between areas and using different modes of transport used for commuting.

Although our focus is on the advantages that these new methods can bring to the analysis of commuting data, some interesting findings arise. Both the number of commutes and the distance travelled by commuters have increased markedly since 1996, particularly around the largest cities of the Auckland, Wellington and Christchurch. Labour markets centred on these cities go well beyond territorial authority boundaries and, particularly in the Auckland case, are becoming increasingly polycentric. Data visualisation makes the exploration of these patterns much more accessible.

\section{Introduction}

The rapid expansion of cities, combined with development of fast and efficient transport in the 20th and early 21 st centuries, has transformed commuting patterns. While the population of cities has grown, the population on the periphery has often expanded at a higher rate. As cities have grown and sprawled, the extent of commuting between city centres and the periphery has increased. Until recently, commuting patterns have been difficult to observe and analyse but new data visualisation techniques can offer insights into these patterns. This paper discusses these new methodologies and examines some of the patterns these methodologies have revealed.

Researchers in the United Kingdom and United States have used commuting information to examine the changing nature of cities. Much information on commuting flows comes from population censuses, although they are able to gain some additional data from travel surveys (Guiliano and Narayan, 2003). Some researchers in the United Kingdom have argued that the increasing tendency of people to live and work at the urban periphery symbolises a significant shift in life-work patterns. Green (2008) suggests that this has resulted in a rise in the importance of "city states", which have increasingly begun to dominate the human landscape of Britain. Research in the United States has identified similar tendencies, including a situation where urban rural boundaries no longer exist as a strict dichotomy ; instead they are blurred. Rurality is now seen as a continuum rather than a distinct state (Hugo et al., 2003. Nechyba and Walsh, 2004). New Zealand has not been excluded from this shift in settlement patterns. In both Europe and the United States cities are no longer following mono-nucleaic forms and are becoming polycentric or poly-nucleaic in structure. Hugo et al. (2003) see the exploration of commuting flows as essential for developing understanding of these new and more complex settlement patterns.

In New Zealand, the population census is the only source of detailed commuting statistics. Census datasets have been used by local government for planning purposes but until recently there has been little statistical analysis of commuting flows except for the work of Morrison (1994). The main studies have concentrated on creating labour market areas in order to gain a better understanding of the geographical distribution of employment and commuting (see Newell and Papps, 2001, Newell and Perry, 2003).

Attempting to analyse commuting flows has been problematic because of the enormous size and complexity of the datasets, especially at small area level. Capturing the complex, multi-dimensional nature of human settlement and movement patterns can be challenging using traditional methods of statistical analysis. Increasingly, geographers have availed themselves of spatial analysis tools such as Geographic Information Systems (GIS) in order to understand and explore these large and complex data sets, but there has been little work to visualise inter-area flows within these systems. 


\section{Objectives}

This paper has two main objectives. The first is to illustrate how spatial visualisation methods can improve our ability to explore commuting in the form of very large origin-destination matrices. We do this through the application of a series of methodologies such as the generation of exploratory labour market areas and the deployment of flow mapping tools. Our second objective is to use these methodologies in conjunction with more established techniques to examine labour market patterns in 2006 and whether these have changed over time. These methodologies will allow us to create a better understanding of the dynamic nature of cities and how they interact with surrounding areas.

The following questions help us to explore these issues and to demonstrate the utility of visualisation techniques to analyse these complex data sets. What does information about distance travelled tell us about changing commuting patterns? Do people travel longer distances to access employment? Are the main cities of Auckland. Wellington and Christchurch becoming more polycentric or do commuting patterns vary by city and by personal characteristics such as occupation? Lastly, what do these new methods tell us about travel patterns between home and workplace and modes of transport used?

\section{Visualising geographical flows}

Despite the widespread availability of computer software for the display and analysis of geographical data, the visualisation of flows between areas (such as the movement of people or commodities) remains poorly supported in most Geographical Information System (GIS) packages. While the ubiquitous choropleth (area class) map allows areas to be shaded by the amount of inflow or outflow they exhibit, this illustrates the results of movements rather than the movements themselves (Tobler, 2003a).

Commuting and migration flows are obtainable from statistical data sources such as the census of population, but present considerable interpretational difficulties for the analyst who wishes to explore them visually. A typical description of these flows is expressed as an array of numbers giving the quantity of movement between each pair of areas. Such arrays quickly become unwieldy when the number of areas under consideration is large. In New Zealand, the analysis of commuting flows at Census Area Unit level requires the treatment of a matrix with more than three million cells. Meaningful analysis of such datasets is very difficult.

There is an established tradition for graphing flows on maps. Graphical tools for flow mapping were first deployed in the 19th century (see for example Tufte (1983) and his discussion of Charles Minard's map of the Napoleonic campaign in Russia) and have seen sporadic use since, notably in the study of transportation networks and public transit movements (Tobler, 2003b). In such maps, areas between which movement occurs are connected typically by a line or band whose colour or width represents the quantity moved (Tobler, 2003b).

Various attempts have been made to produce effective visualisations of flow data on maps. The pioneering work of the Centre for Spatially Integrated Social Science via the FlowMapper project (Tobler, 2003a) and parallel initiatives such as the Flowmap program (Geertman et al., 2003) allow for the preparation of static flow maps and analytical maps based on flows for large numbers of areas and interactions. However, these packages cannot provide a dynamic means of visualisation, making it difficult to interpret complex flow patterns and to consider subsets of flows, especially in urban areas. In addition, the computation time to generate such maps for large numbers of areas can be prohibitive and the resulting outputs are also difficult to interpret.

Recent advances in web-based visualisation, in particular the development of open source standards for high quality, dynamic graphics such as the Scalable Vector Graphics recommendation (W3C, 2003) and related technologies such as ECMAScript (ECMA, 1999) and Extensible Markup Language (XML) (W3C, 2006) mean that it is now possible to construct dynamic visualisation tools for geographical flows between areas. Such tools can be deployed within a standard web browser environment, making them highly accessible and flexible.

The Office for National Statistics in the United Kingdom recently released CommuterView (ONS, 2008), an interactive tool for visualising travel to work information from the UK 2001 Census of Population using open source tools. We have adapted the CommuterView engine to operate on New Zealand datasets, and used it to visualise journey to work data from the 1996 and 2006 censuses of population for the purposes of this paper.

\section{Data sources and methodology}

The source data for this project come from the New Zealand Census of Population for 1996 and 2006. All employed adults in New Zealand were asked to give "the full name of the business or employer you mostly worked at" and where that workplace was located. This information, combined with the location of their usual place of residence, forms our primary dataset.

Figure 1: Place of work question from the census form

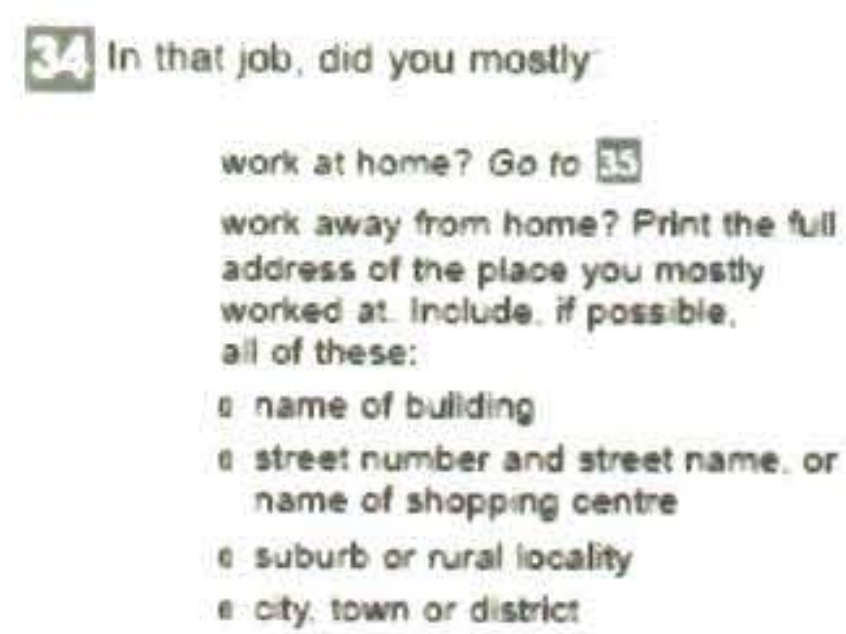




\section{Calculation of distance travelled}

Because census responses are coded to areas rather than to the physical addresses of properties and because there is presently no means to obtain address-level geographical references for responses, we have had to approximate the distances travelled by commuters. This has been carried out by using two simple proxy measures which are illustrated in Figure 2. For commutes between areas, we used the straight-line (Euclidean) distance between the geometric centroids of Area Units. Where travel occurred within a single area unit, we used a value equal to half the diagonal distance across the minimum bounding rectangle that enclosed the Area Unit.

\section{Figure 2: Calculation of centroid to centroid and} within area distance travelled proxy measures for Area Units.
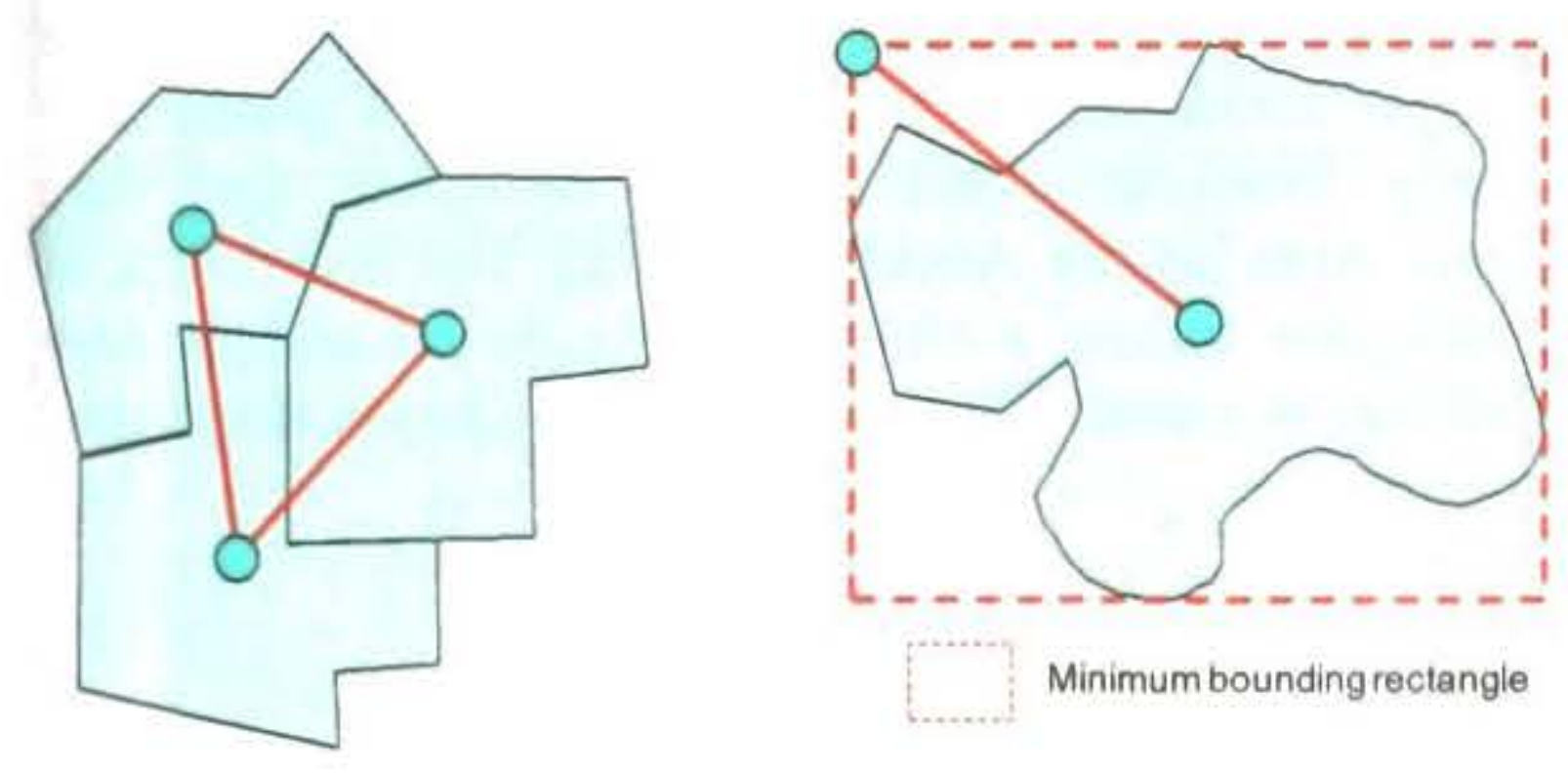

These proxy distances work reasonably well when area units are small. However, they are less reliable in large rural area units. We return to this issue later when we consider the distance travelled by commuters in different professional groups.

\section{Flow-based delineation of local labour market areas}

There is a rich literature on the delineation of functional areas for the study of commuting patterns. The most well-known approach is probably the Travel To Work Area (TTWA) generation algorithm put forward by Coombes and Openshaw (1986) and implemented in the United Kingdom for successive decennial censuses (Coombes et al., 1987, Coombes, 2002). This method has also been applied in other countries, including New Zealand (see for example Papps and Newell, 2001 and Bill et al., 2008). The algorithm focuses on the construction of zones within whose boundaries a specified proportion of the population both live and work.

While the TTWA algorithm is very effective at delineating large catchment regions for employment and travel to work (the threshold value is usually about 70 percent) it can be less useful for exploring the delineation of local labour markets. This is because such areas can be too small to achieve the global threshold value and tend to be subsumed into larger areas. This limitation may be relevant in New Zealand, because the economic landscape is dominated by the urban centres of Auckland, Wellington and Christchurch and these concentrations of employment activity may dominate smaller zones that may also be of interest.
The approach we have taken focuses simply on the magnitude of inbound commuter flows rather than on containment. It draws on the use of a network analysis technique called Primary Linkage Analysis (PLA) (see Nystuen and Dacey, 1961, Davis and Robinson, 1968, Haggett et al., 1977) which has been applied by geographers and planners in the construction of catchment areas based on the magnitude of inflows. It evolved in the 1960s and 1970s in the study of hierarchies of urban dominance, and has also seen application in the delineation of zones of communication for telephone networks, for example.

We applied the technique to commuter flow information for both 1996 and 2006 (see appendix). The resulting catchment areas and the observed changes in their configuration between 1996 and 2006 are discussed in the results section of the paper.

\section{Results}

We begin by looking at changes in the overall pattern of commuting behaviour between 1996 and 2006.

Figure 3 shows changes in the number of inbound commuters by Urban-Rural Classification categories. The rise in the number of commuters into Main Urban Areas between 1996 and 2006 is dramatic. This represents a 21 percent increase from the 1996 total, which is much higher than the population growth for Main Urban Areas in this period (13.9 percent). In 1996, Main Urban Area inflows accounted for 73.1 percent of all commuter journeys. In 2006, this rose to 75 percent.

Figure 3: Inbound commuters and the Urban-Rural Classification

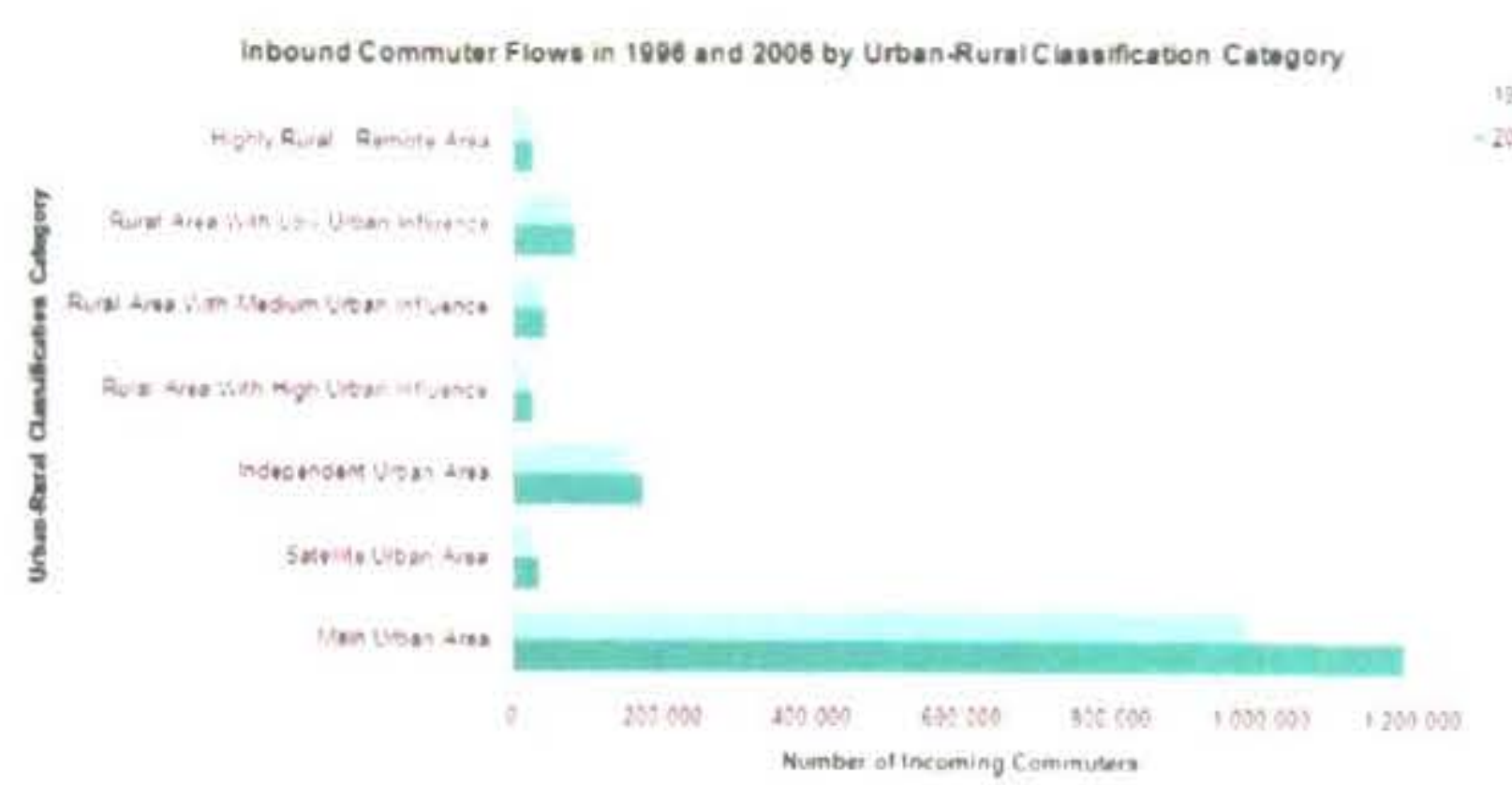

There is considerable regional variation in these patterns. For example, there has been a substantial increase in the number of people commuting to the main cities in the Auckland and Wellington and Canterbury regions (22.8, 11.0 and 15.6 percent respectively) but not in the proportion of people. In some of the smaller regions, in particular Bay of Plenty, Waikato and ManawatuWanganui both the number and proportion of people working in the main cities have increased. Tauranga had the most spectacular shift with a 47.9 percent increase in numbers between 1996 and 2006. 
Figure 4: Workers in the main city of their region: proportions in 1996 and 2006

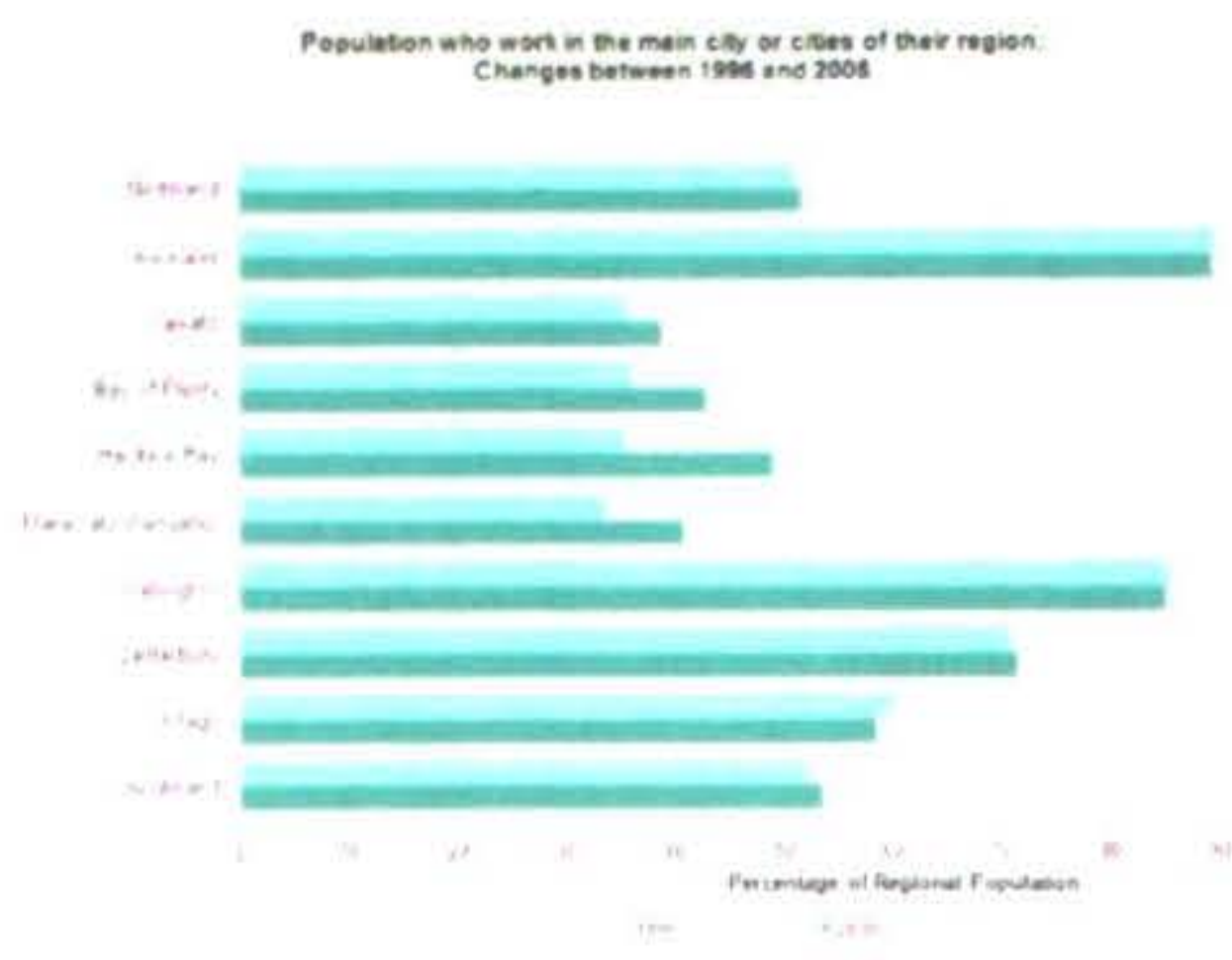

Figure 5: Distance travelled to work in major cities ${ }^{1}$.

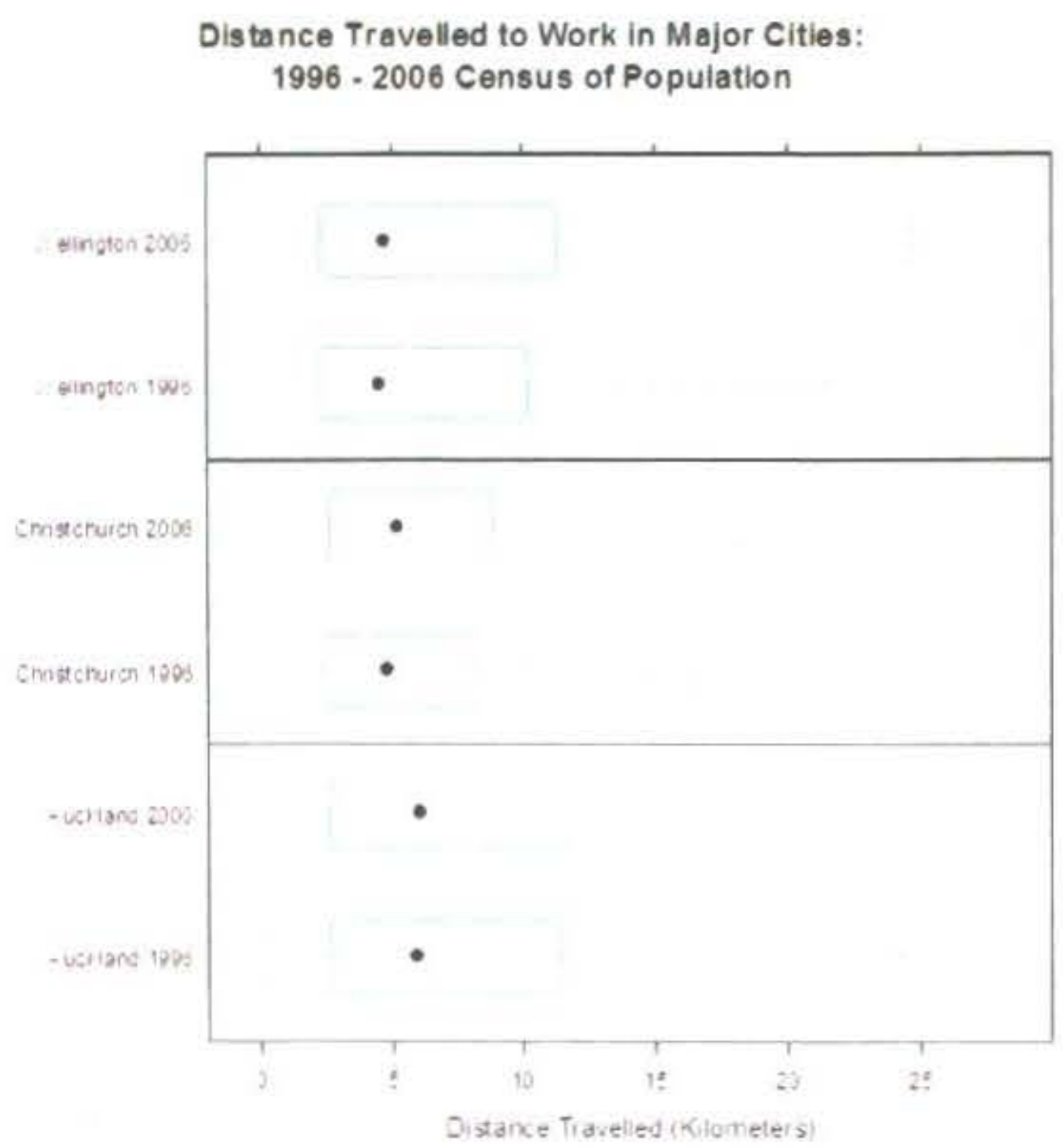

Median distance travelled has remained stable in the ten year intercensal period. but there are slight increases in the median in Christchurch and Auckland. The distribution of the distance covered by commuters has, however, widened in all cases. This effect is most marked in Wellington, where the interquartile range has increased noticeably. The distance travelled by commuters tends to be longest in Auckland, a pattern that has also been seen in the polycentric cities of the Netherlands (Schwanen et al., 2004).

\section{Commuting in Auckland, Wellington and Christchurch}

The Auckland metropolis has the largest concentration of population in New Zealand and is New Zealand's only urban area with more than a million people. By 2006, the Auckland metropolis constituted the largest labour market within New Zealand, almost three times as large as that of the Wellington metropolis or Christchurch city. In comparison the next largest cities of Hamilton and Dunedin employed just 3.6 percent and 3.0 percent respectively of the national employed population.
Figure 6: Percentage of employed population in major urban centres

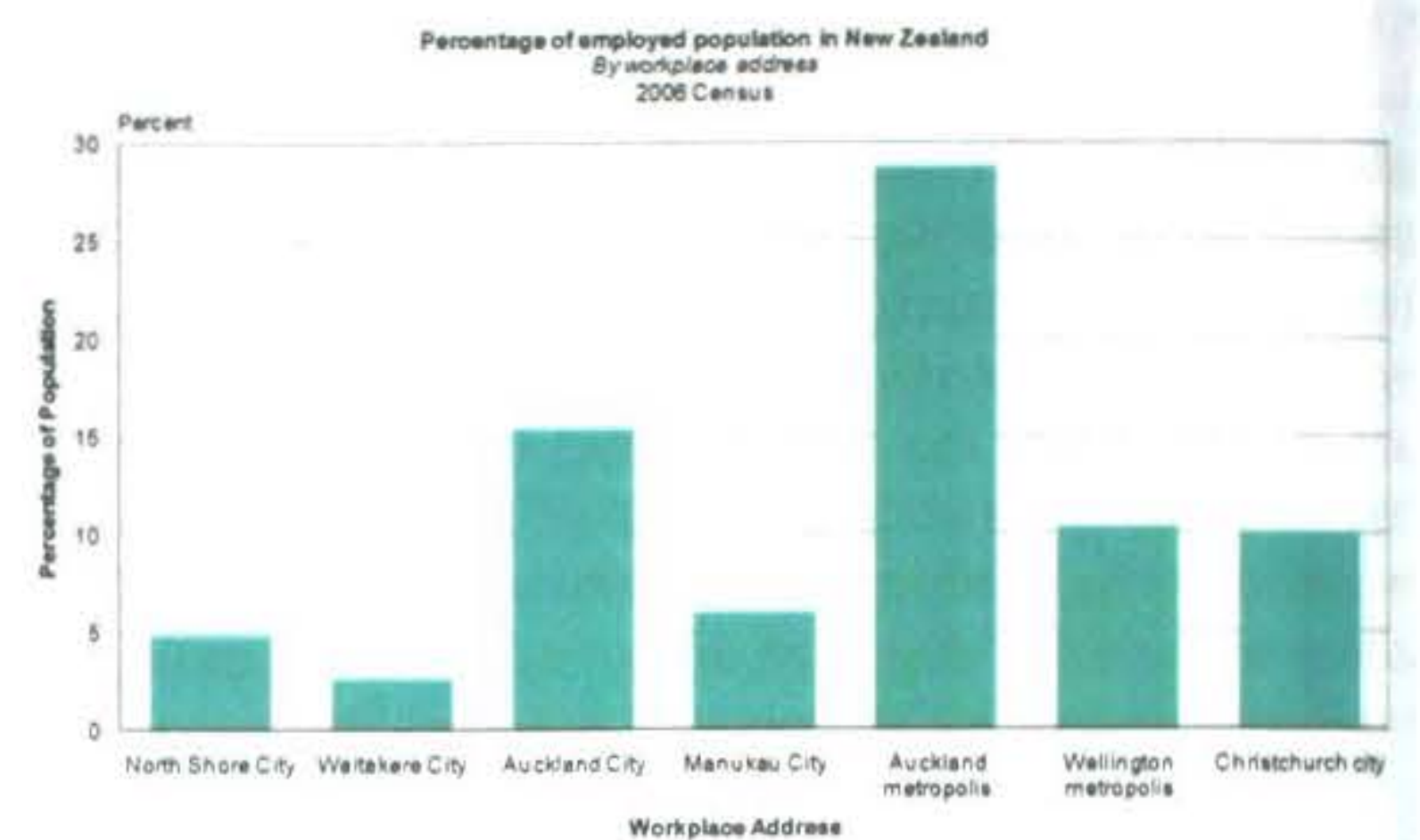

The four territorial authorities that constitute the Auckland metropolis are North Shore, Auckland, Waitakere and Manukau cities. These cities have separate administrations and identities but in practice are closely interlinked and together constitute the Main Urban Area of the Auckland region. The four cities of Wellington follow a similar configuration and in both Wellington and Auckland, one city dominates employment.

Figure 7: Dominance of Auckland City in the commuting patterns of the four cities of Auckland

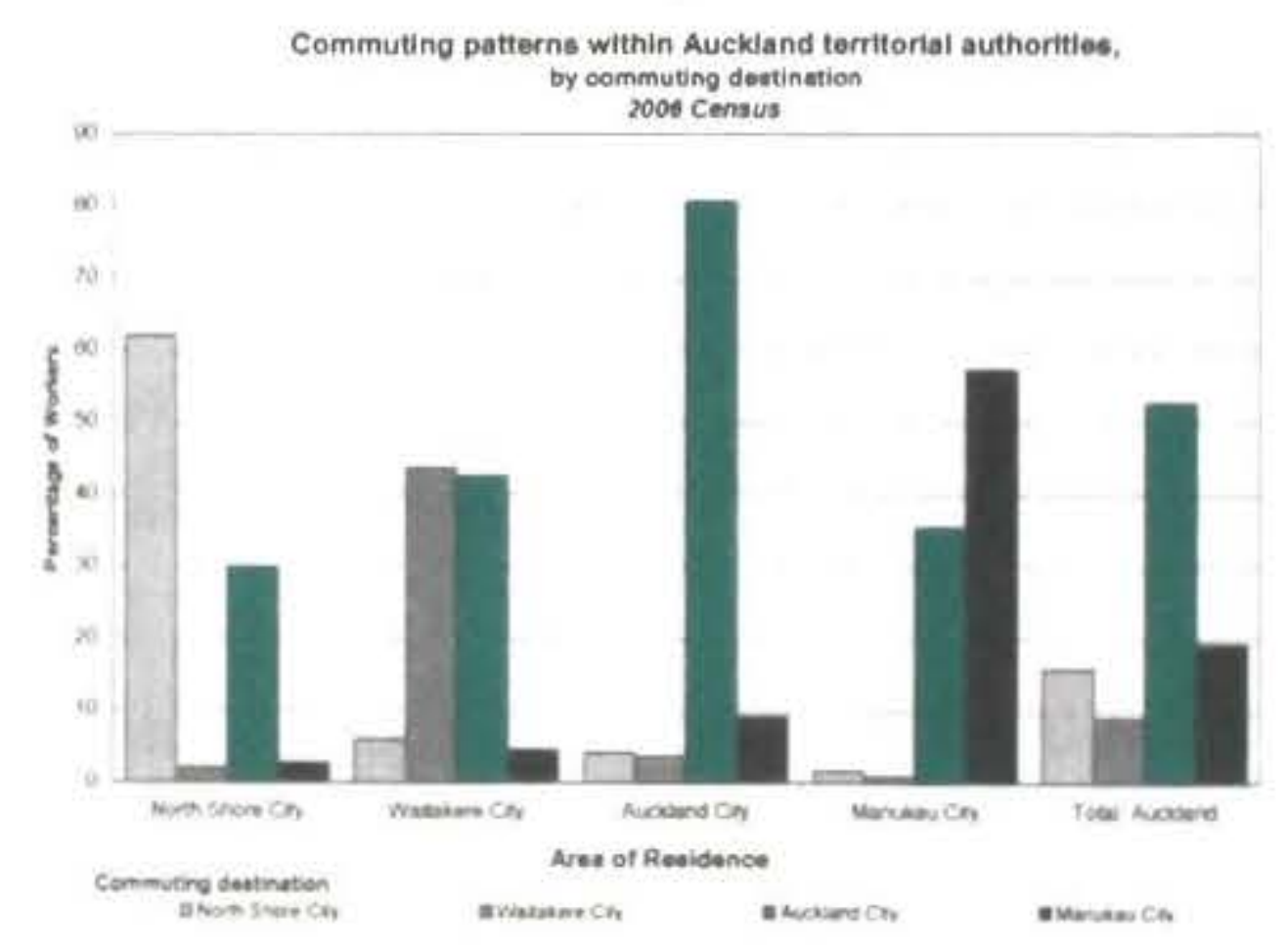

Figure 8: Dominance of Wellington City in the commuting patterns of the wider Wellington region

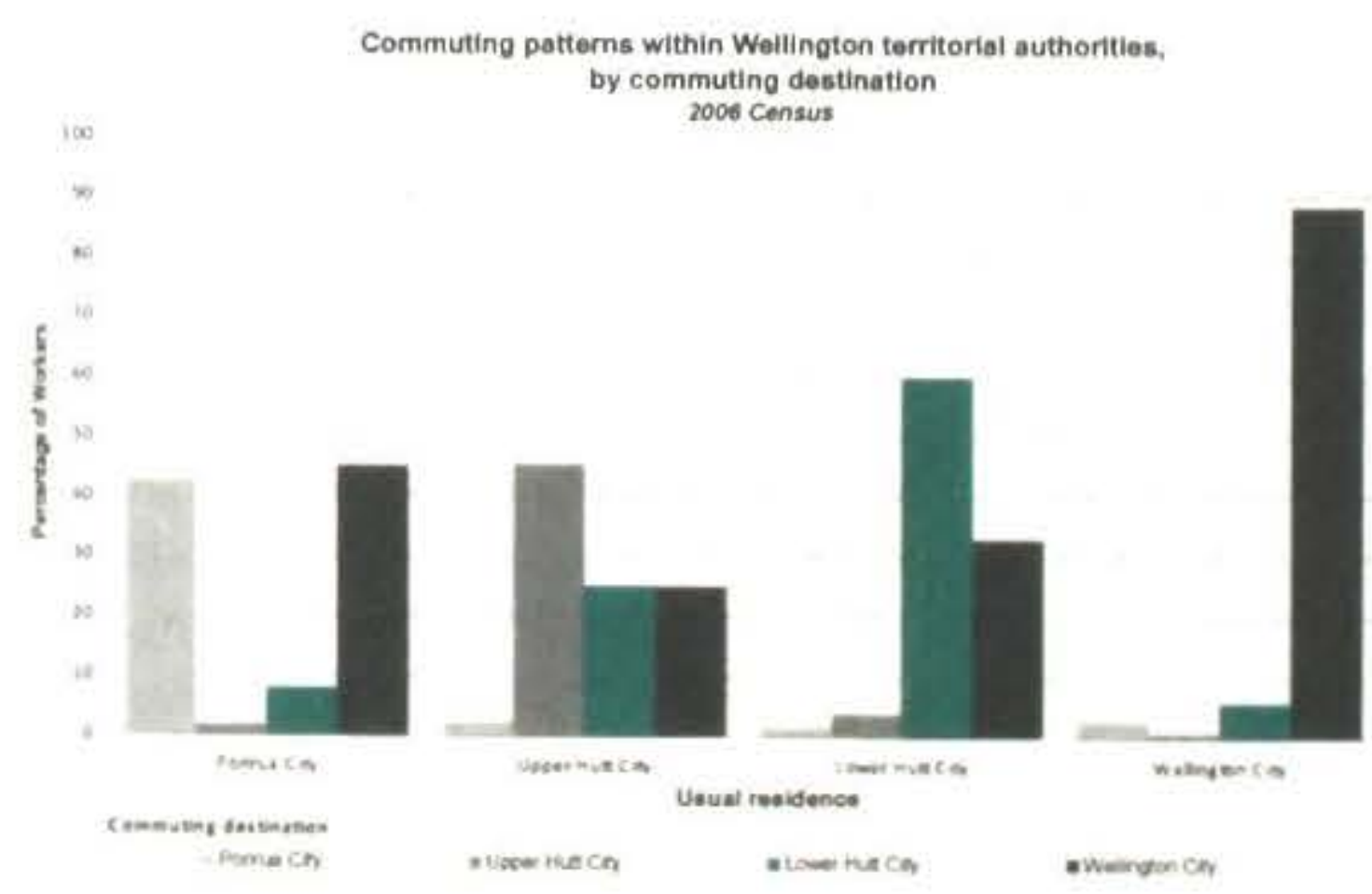

Over time, Auckland city's dominance decreased slightly, however, from employing 50.5 percent of the region's population in 1996 to 47.8 percent in 2006. In contrast Wellington city's share of the region's employed 
population increased very slightly, from 53.6 percent to 55.3 percent.

\section{Changes in local commuting areas, 1996-2006}

In the next section we consider how flow-based local commuter areas defined around Auckland, Wellington and Christchurch have changed between 1996 and 2006. These are the zones of influence that were delineated using the primary linkage analysis method described above. On the maps that follow, each zone is shaded in a different colour to aid discrimination between them. The area unit which is the order 1 hub that dominates the zone contains a red circle at its geographical centroid with a size proportional to the magnitude of commuter inflow.

Figure 9 shows the commuter catchments in Auckland in 1996. The conurbation is dominated by the Auckland Central West area unit whose influence extends out to North Harbour and East Tamaki. Smaller hubs are present in Stanley Bay and Lynnmall, with another large hub in Manukau Central.

Figure 9: Local commuting zones in Auckland, 1996

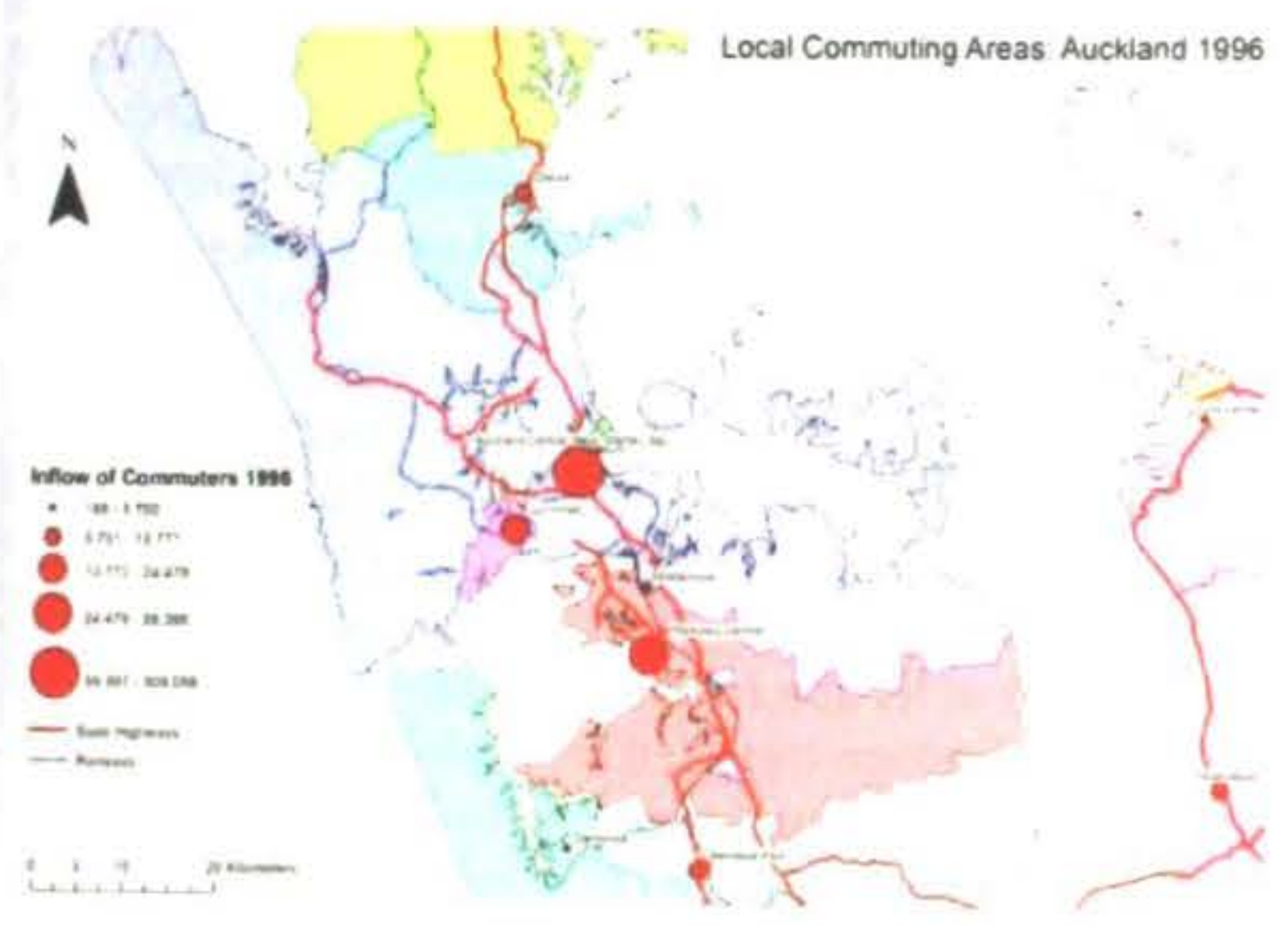

By 2006, the pattern is quite different. The Auckland Central West zone has fragmented. North Harbour East has now emerged as an important hub in its own right, while the Manukau catchment has been divided into a small commuter zone around Mount Wellington and an expanded zone around East Tamaki.

Figure 10: Local commuting zones in Auckland, 2006

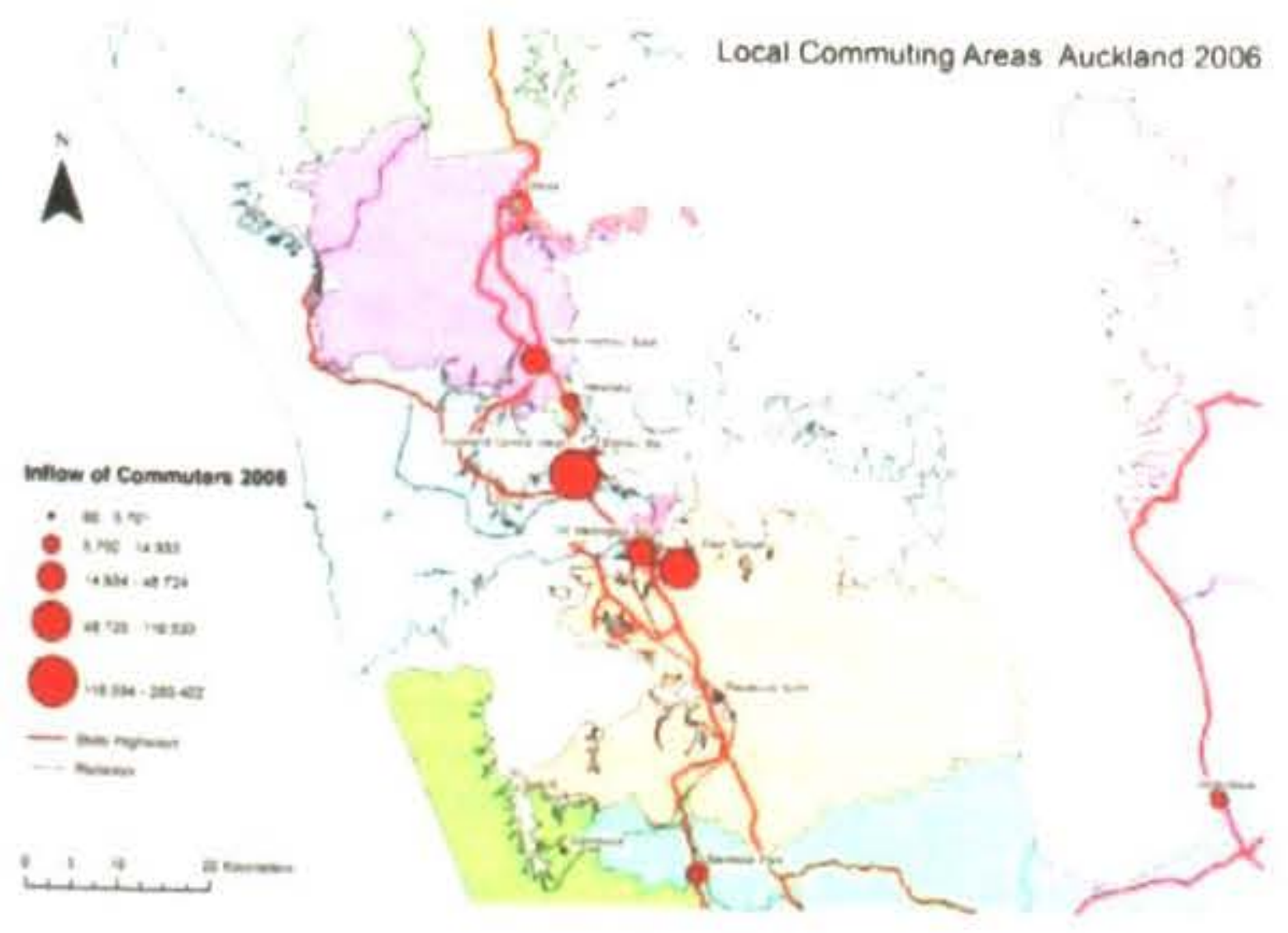

The pattern of change in Wellington is also of interest, although here expansion is constrained by the physical geography of the region.

Figure 11: Local commuting zones in Wellington, 1996

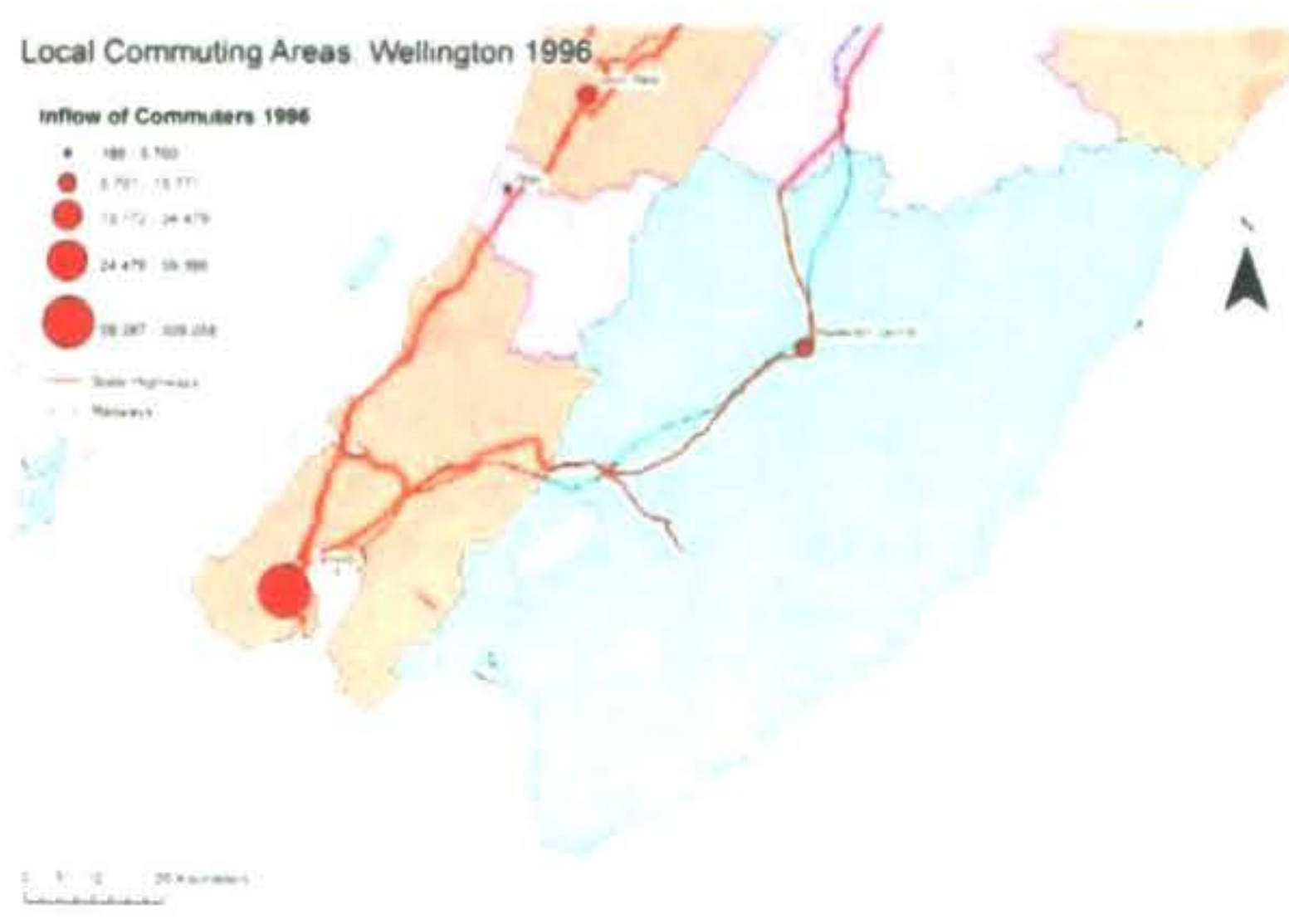

The dominant area unit in both years is Lambton, but note how the influence of Lambton has expanded northwards in 2006 to subsume the previously self-contained zone around Otaki.

Figure 12: Local commuting zones in Wellington, 2006

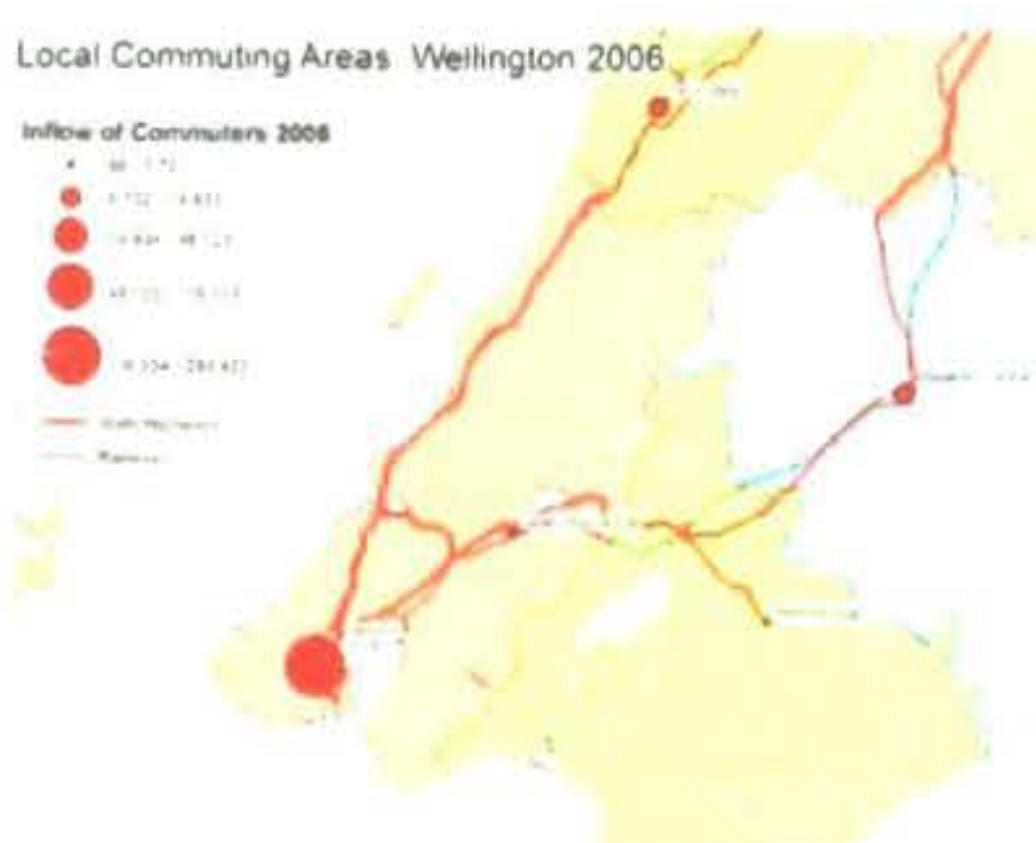

A

Also of note is the emergence of Martinborough as a commuting zone in its own right, subdividing from the 1996 zone around Masterton.

The pattern of change in Christchurch echoes that seen in Auckland, although on a smaller scale. The dominance of Cathedral Square and the CBD is evident in both years, but by 2006 Darfield and Oxford have emerged as new catchments. 
Figure 13: Local commuting zones in Christchurch, 1996

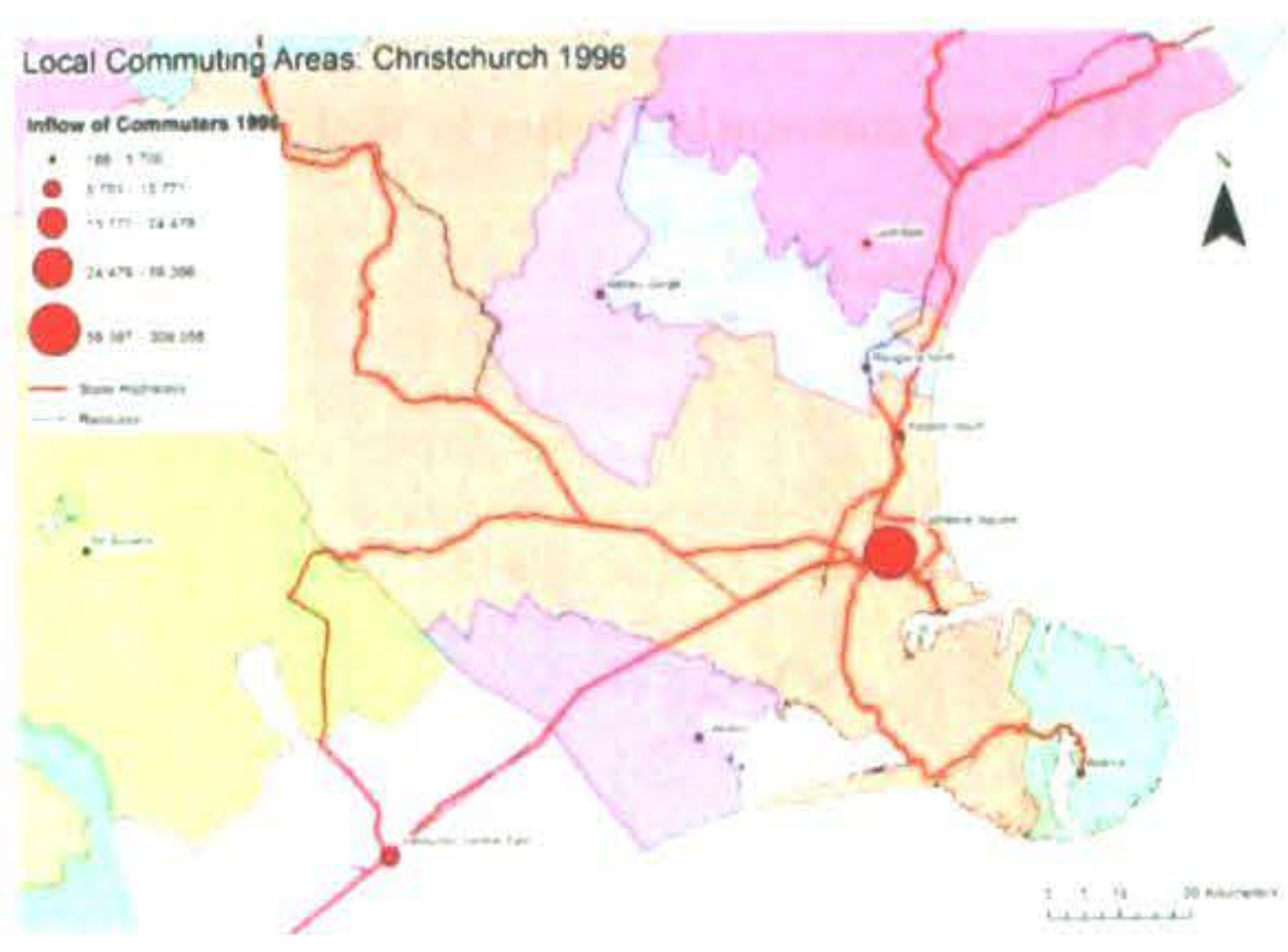

Figure 14: Local commuting zones in Christchurch, 2006

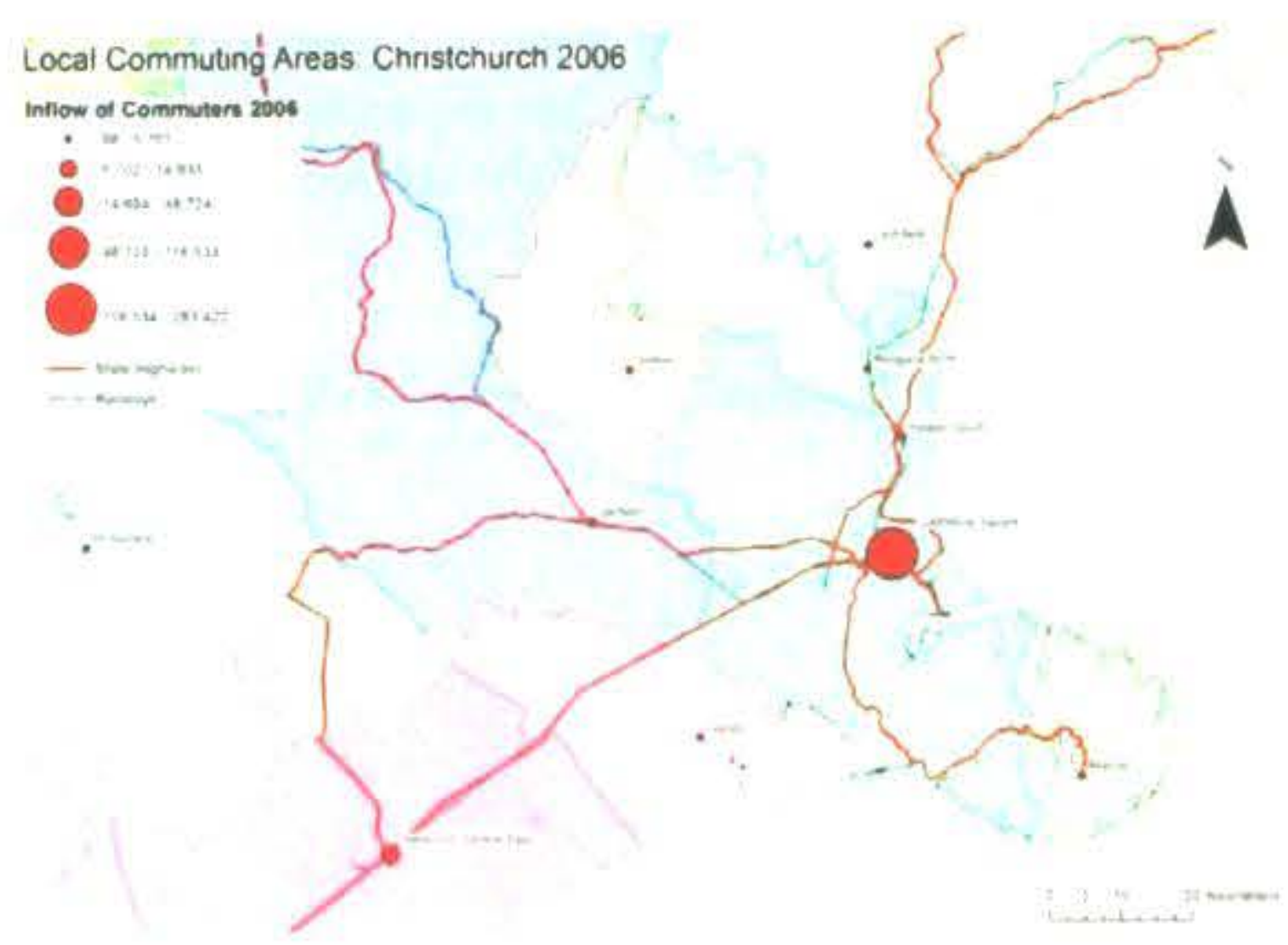

These results seem to be in line with current ideas about the propensity of large cities to become polycentric, with multiple hubs of economic activity. This effect is seen most markedly in Auckland, where the emergence of North Harbour, Mount Wellington and East Tamaki go alongside a reduction in the influence of Auckland Central.

\section{Characteristics of commuters}

Census commuting statistics offer us a rich set of information about the travel patterns of individuals. Here, we consider the socio-economic characteristics of commuters alongside information about the journeys that they make.

In the next section, we explore differences in the distances covered by subsets of the commuting population. We first consider occupational groups, and then move on to the mode of transport used in the journey to work.
Figure 15: Distance travelled by profession

Boxplots of Distance Travelled to Work by Profession: Change between 1996 and 2006 Censuses of Population

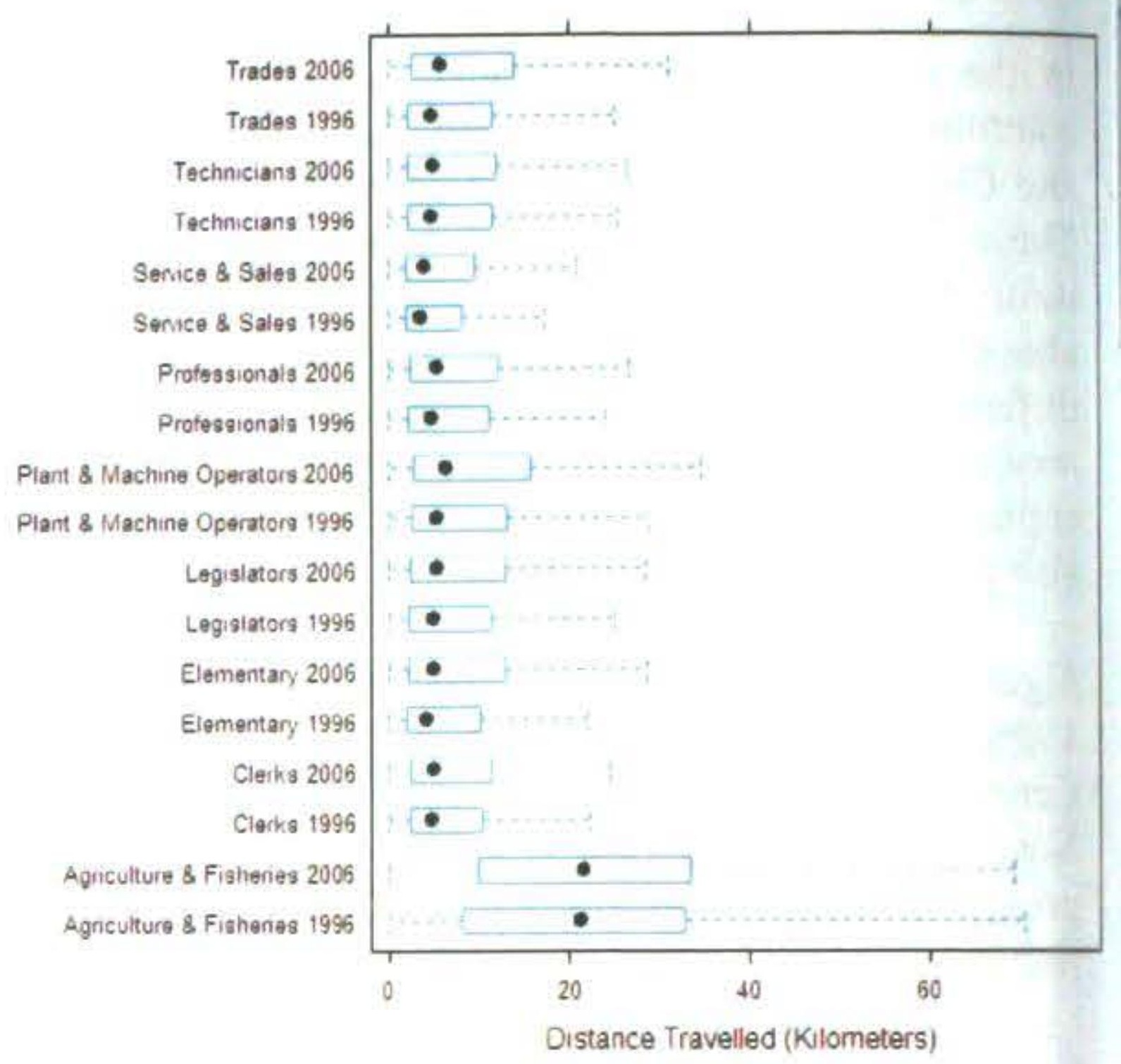

Figure 15 shows that, in general, people are travelling further to work in 2006 than they did in 1996. All of the professional groups we considered showed an increase in median distance travelled. This is particularly clear in the case of the Trades, Service \& Sales and Plant Operators groups.

The distance travelled pattern for workers in the Agriculture and Fisheries group needs elaboration. The observed pattern is likely to be partly due to limitations of the distance approximation that our methodology utilised. Because area units in rural areas tend to be very large, our proxies for distance travelled to work both between and within area units in rural areas are likely to over-estimate the true figure.

\section{Figure 16: Distance travelled by mode of transport}

Boxplots of Distance Travelled to Work by Transport Mode: Changes between 1996 and 2006 Censuses of Population

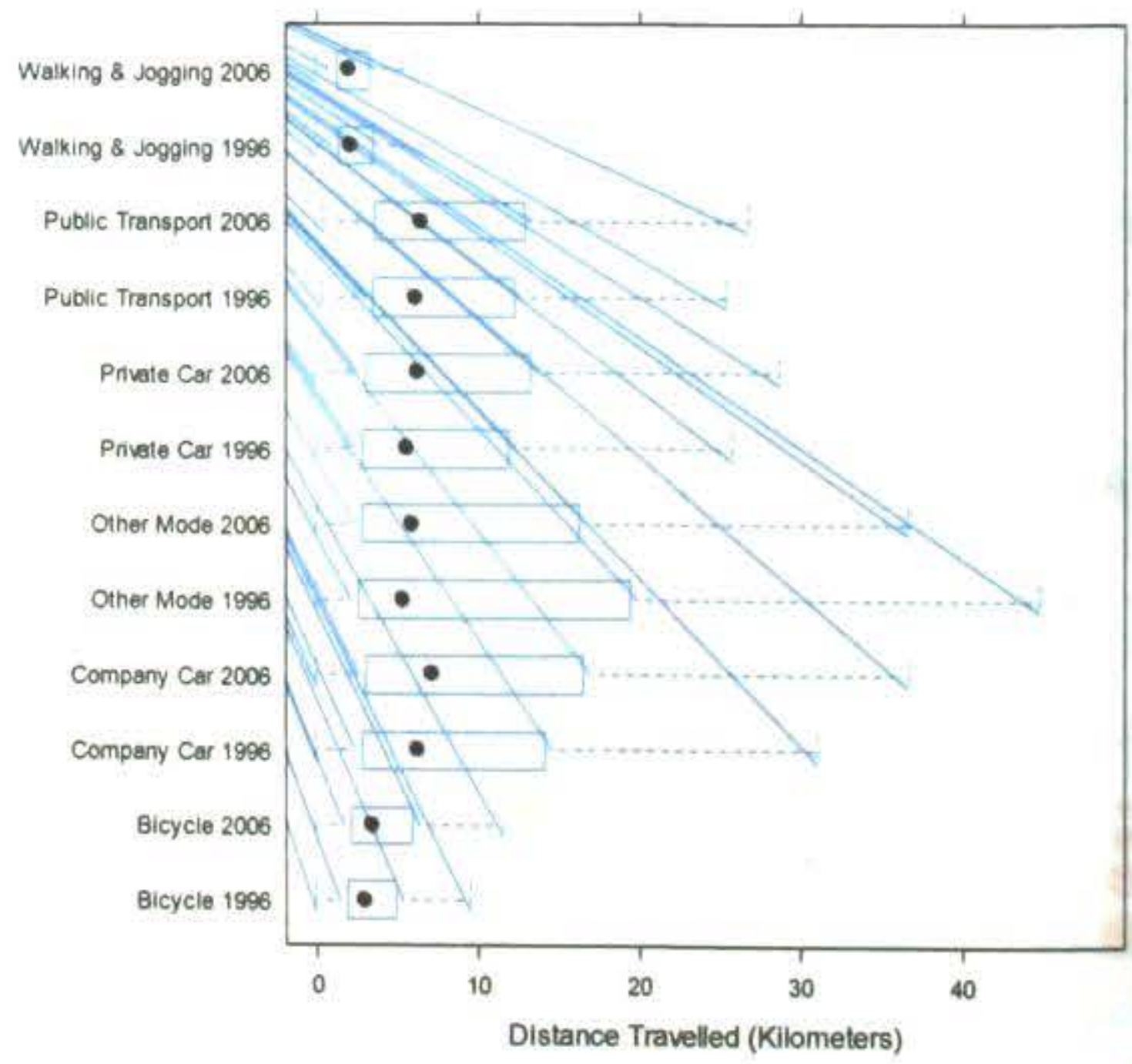


Figure 16 shows similar findings to Figure 15 . In general, people are travelling further in 2006 than they did in 1996. All modes of transport except Walking and Other show an increase in the median distance travelled and the distributions of those distances have increased in width. This is particularly clear in the case of company and private car journeys.

Figure 17: Proportion of commuters using public transport in local commuting areas in 2006

Local Commuting Areas: New Zealand 2006

sover $2000 \mathrm{C}$ minus a pareas

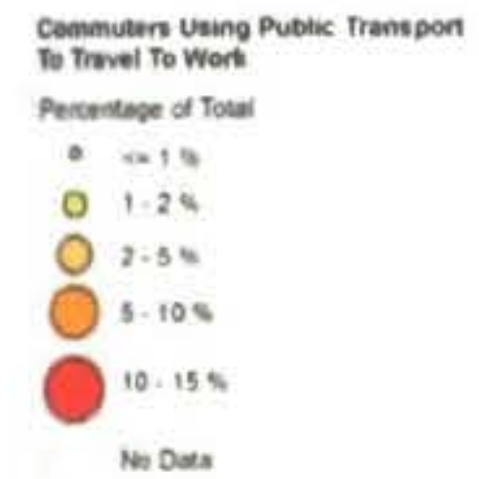

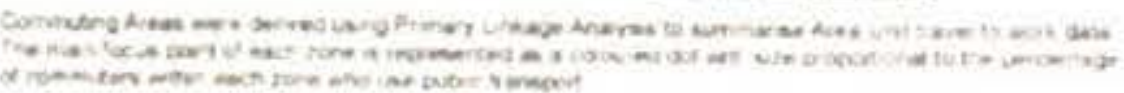

On census day 2006, people commuting into the Wellington metropolis had higher public transport use than residents ( 25.7 percent compared with 16.2 percent). Just 4 percent of people living outside the Auckland metropolis used public transport (compared with 6.6 percent within). Less than 1 percent of people outside Christchurch used public transport to commute to the city.

\section{Spider diagrams and the visualisation of flows}

One of the goals of this paper was to consider how improvements in visualisation technology could enhance our understanding of commuting patterns. A key limitation of area-based mapping techniques such as the choropleth representation of flows is that they are unable to show the flows themselves, focusing instead on their results. This limits our ability to understand the geography of inflows and outflows and the interplay of movement between particular area units.

Spider diagrams are a flexible and powerful means of allowing us to look more closely at the spatial pattern of commuter flows themselves. In the spider representation

implemented here (based on ONS, 2008), an arrow whose thickness and colour is dependent on the number of commuters moving along the flow is used to show movement between two area units. By building up sets of flow arrows in this way, multiple interactions between the areas can be visualised simultaneously and the detailed patterns of interaction between them can be seen. We can demonstrate the utility of this approach with some examples.

Research has already shown that people who use company cars tend to travel further to work. Nationally, just over 11 percent of people said they used a company car as their main means of travel to work on census day. Levels within the Auckland metropolis were fairly similar, although higher for people working in Manukau City and North Shore.

\section{Figure 18: Spider flows of company car commuters in} Auckland, 2006

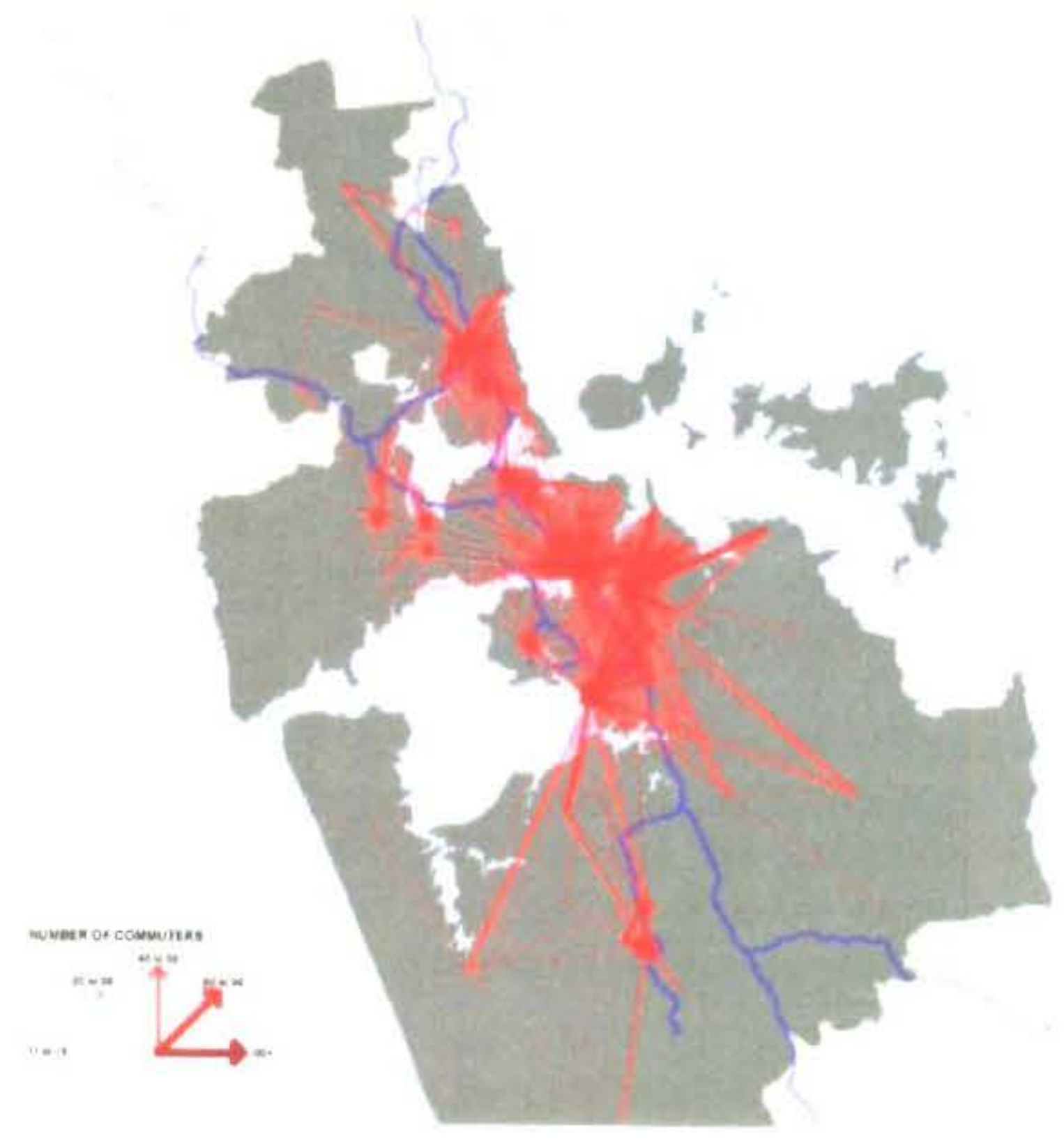

The spider flow visualisation allows us to consider this pattern in more detail. Figure 18 identifies the major destinations for company car users within the Auckland metropolis. There are small hubs present in the North Shore (Westlake, Glenfield North, and North Harbour East). In Auckland City, major company car use is centred on Penrose, Elleslie South and Mt Wellington South. In Manukau, such activity is concentrated in East Tamaki and Manukau Central. 


\section{Figure 19: Company car use by selected industry}

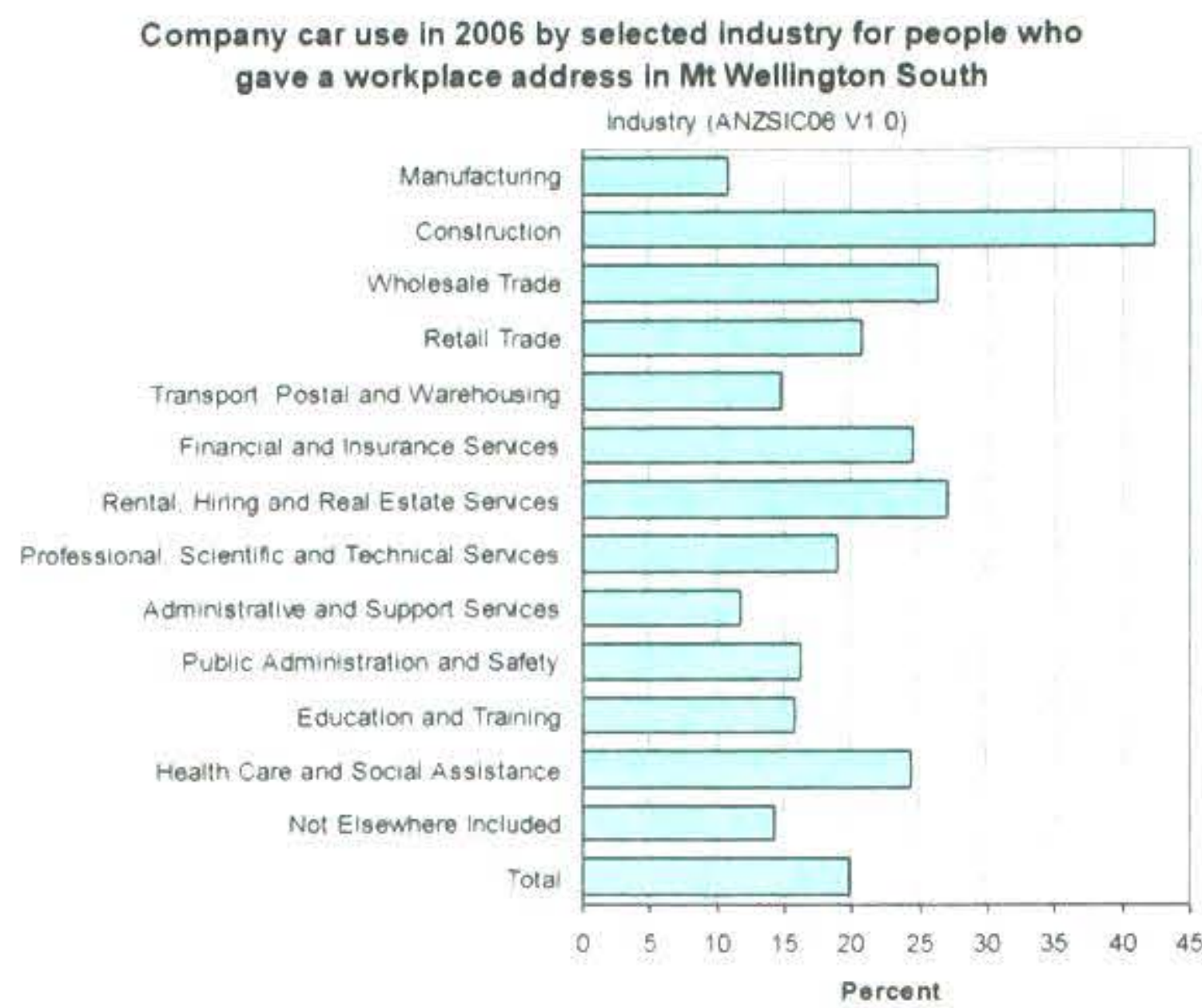

Company car use appears clustered around certain types of work. For example, in Westlake a third of workers who specified a workplace address were in the Health Care and Social Assistance sector, yet among this group company car use was low (less than 2 percent). In contrast, one in six people engaged in manufacturing used a company car to travel to work on census day (approximately 17 percent). In North Shore and Manukau, company car users were predominantly working in manufacturing, construction and the wholesale trade. In an area such as Mt Wellington South (Auckland City) in contrast, there seemed a more even spread of company car usage by industry.

In Figure 20, we consider commuters who walk or jog to work in Wellington. In this case the pattern of flows is much more localised, showing the heaviest concentrations in the inner suburbs of the city but with extensions outward where pedestrian routes make walking feasible.

Figure 20: Walking and jogging to work in Wellington, 2006

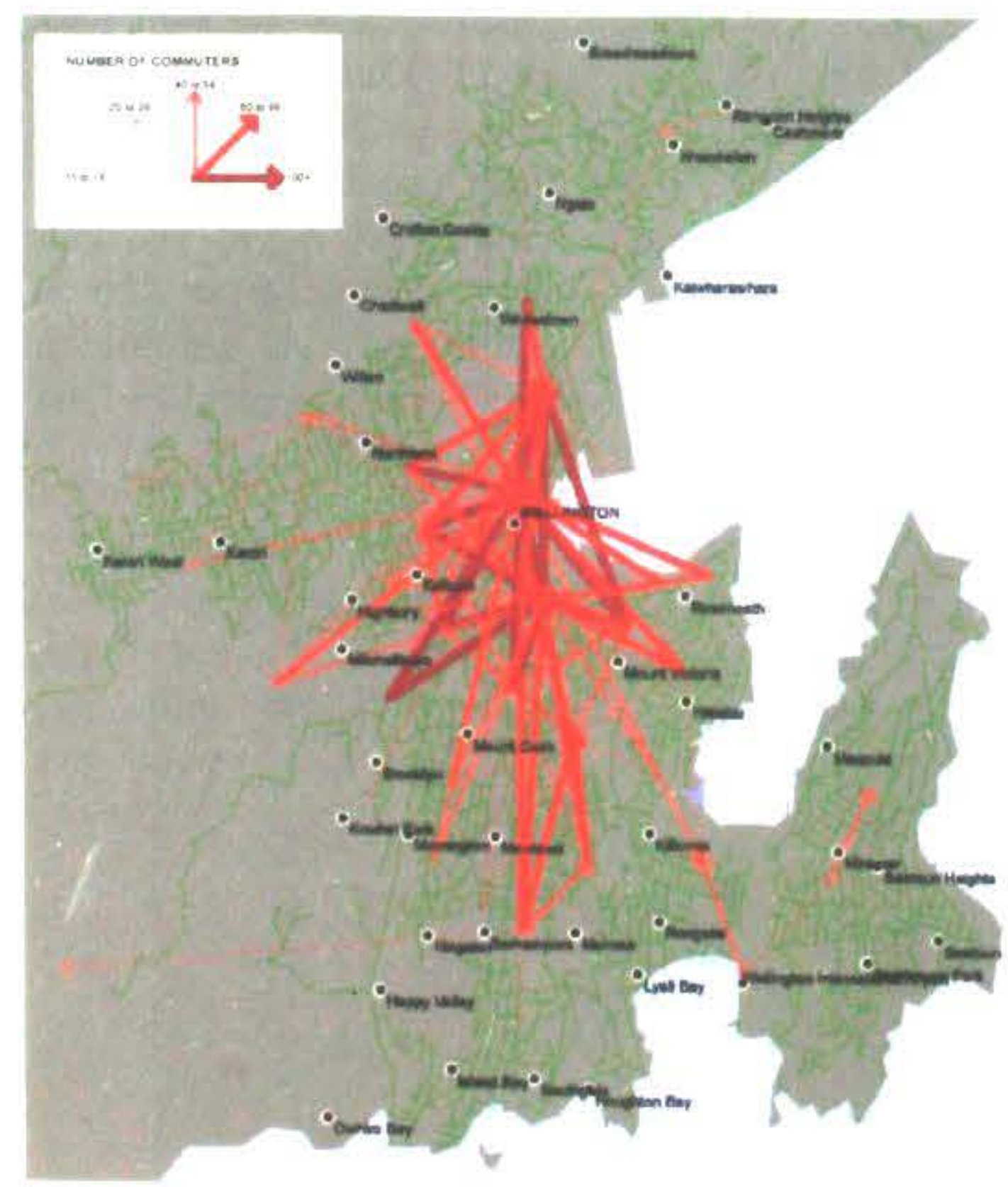

Figure 21 shows the extent of public transport use in the wider Wellington area. Here, the importance of the commuter rail network is clearly visible, allowing inbound commuters to journey from settlements on the Kapiti Coast such as Paraparaumu, Waikanae and Otaki, inland areas like Carterton and the suburban areas of the Upper and Lower Hutt Valley. Similarly, the importance of the bus and rail networks in supporting inbound commuters from settlements like Porirua, Eastbourne and Wainuiomata is evident.

Figure 21: Journeys to work on public transport in Wellington, 2006

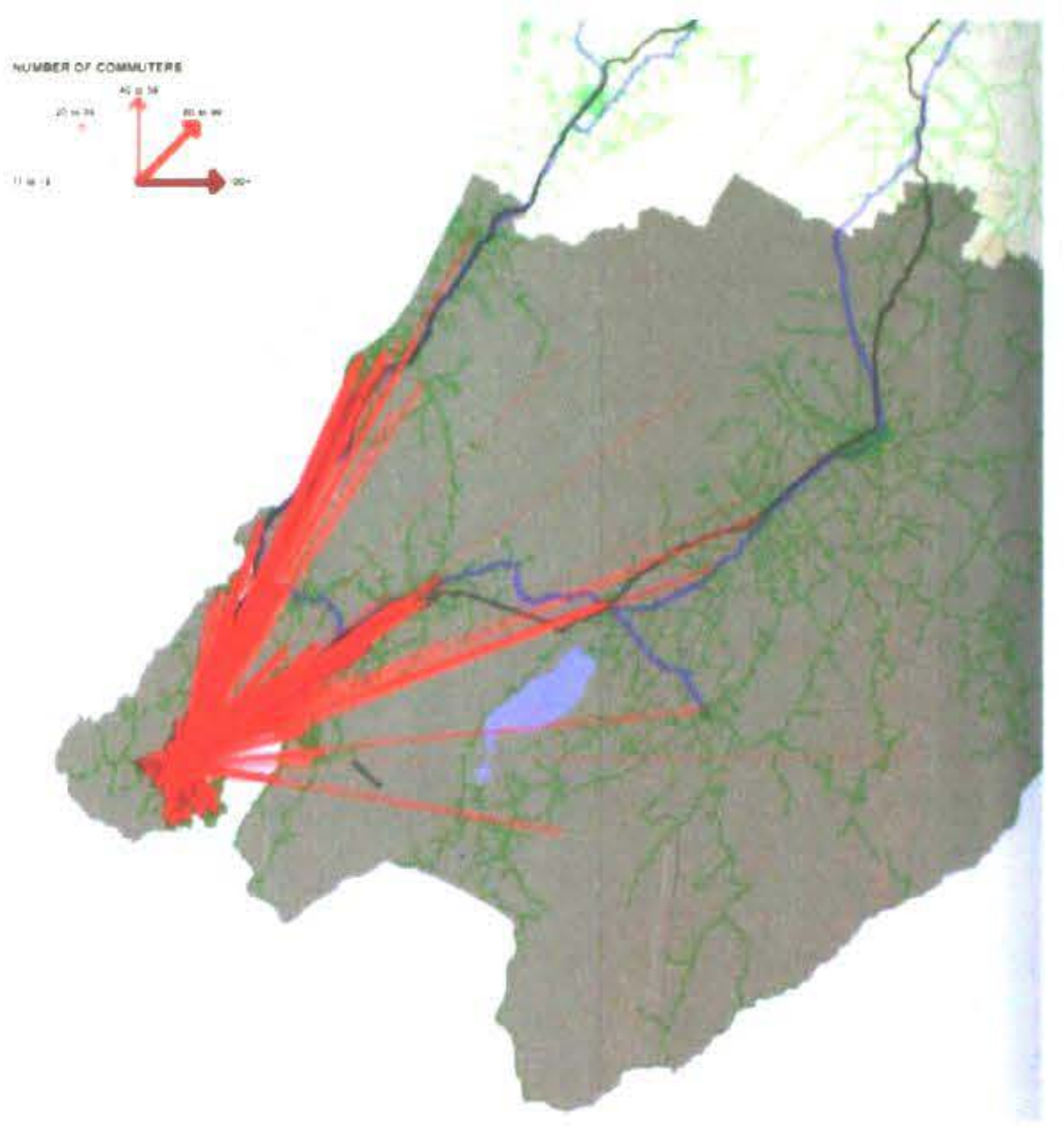

Finally, we consider inbound commuters to Christchurch City. The extension of commuter flows along the state highway networks is clearly visible, as are local workplace hubs around Ashburton and Akaroa.

Figure 22: Journeys into Christchurch City - All modes of transport, 2006

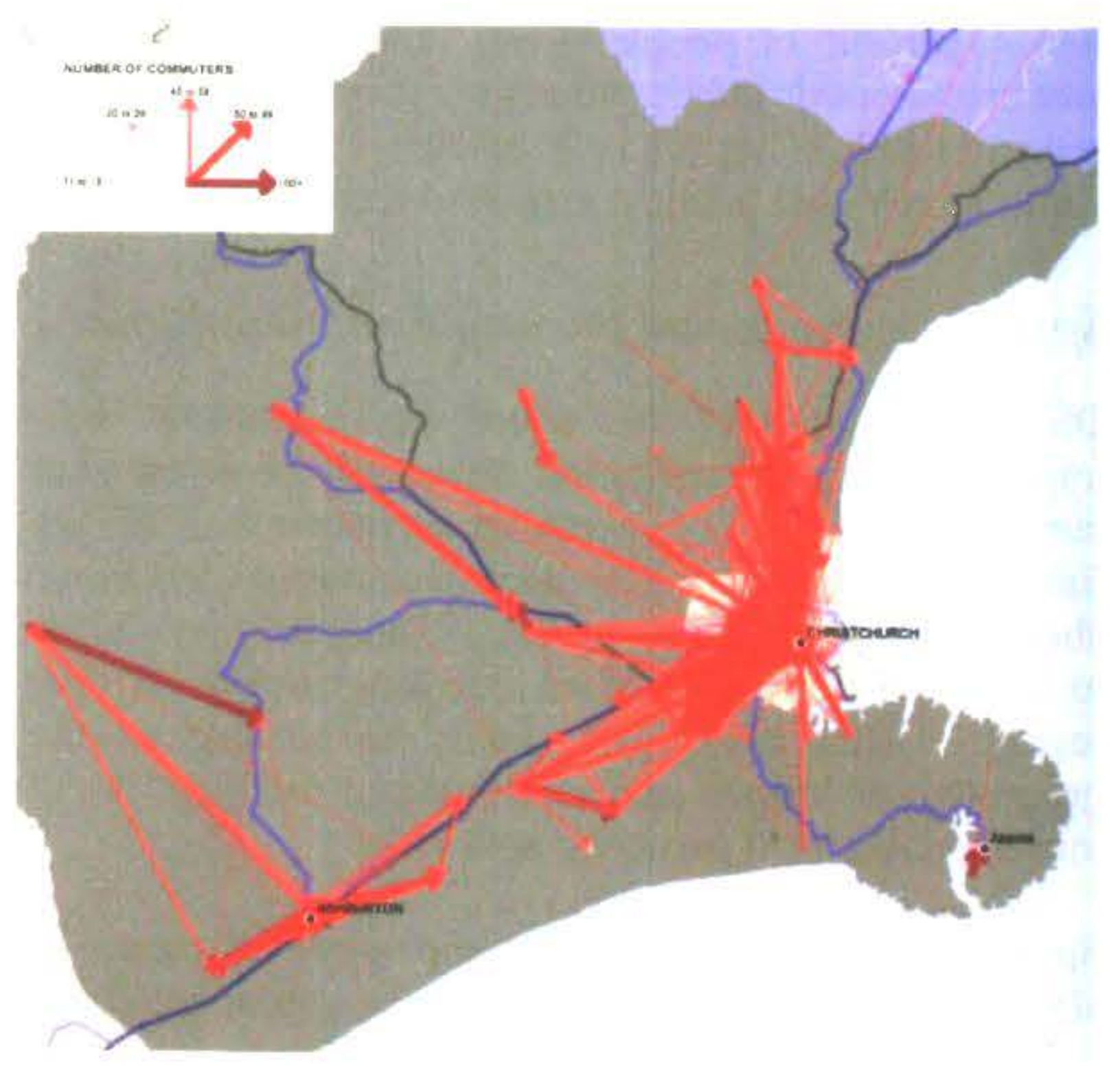




\section{Conclusions}

One of the main objectives of this paper was to introduce new techniques of data visualisation and show how these could be used to examine trends in commuting patterns. The deployment of tools for flow visualisation like the dynamic spider diagram introduces a set of valuable new techniques and demonstrates how they can enhance our understanding of commuting patterns. Exploration of the geography of flows themselves, alongside the characteristics of origins, destinations and the commuters who make the journeys, provides new insight into how local patterns of commuting are evolving and unlocks datasets that were previously quite intractable.

The paper also aimed to examine general trends in commuting and some results are observable from our analysis. The first is that there has been a marked increase in the proportion of population that work in New Zealand's major cities between 1996 and 2006.

The second is that, on average, commuters travelled further in 2006 than they did in 1996 across most modes of transport and all occupation groups. This is coupled with the fact that, except in Wellington, commuting journeys depended almost exclusively on private or company motor vehicles. This topic is of relevance to contemporary interest in the sustainability of our cities and issues of traffic congestion.

The evolution of flow-based commuter zones between 1996 and 2006 suggest an increase in the polycentric configuration of cities in New Zealand, particularly within the Auckland metropolis. This finding is supported by other studies, notably the Auckland Regional Growth Strategy (Regional Growth Forum, 1999) which recognises and encourages polycentric expansion within the Auckland region.

\section{Further work}

The work described here is preliminary. Much more could be done through wider investigation of census travel data. This is a rich data source, linking individual travel patterns with detailed socio-economic characteristics for commuters, origins and destinations. The visualisation tools presented here offer new opportunities to obtain insight into commuter behaviour, and are sufficiently generic that they could be applied to other flow analysis problems (such as the visualisation of census migration patterns). Potential topics include looking at double income commutes to see whether partners follow different commuting patterns and exploring the commuting patterns and workplace characteristics of the poorest and wealthiest groups within New Zealand society.

There are, however, some immediate and practical uses for this research: local authorities require information about commuter flows in order to manage transport planning and support planning. Part of the aim of this project is to distribute Commuterview NZ to local councils and interested researchers within New Zealand.

\section{Note}

1. "Auckland" refers to the four cities of Auckland and "Wellington" includes Wellington City, Lower Hutt, Upper Hutt and Porirua City. Christchurch comprises the Christchurch City Territorial Authority.

\section{References}

Bill, A., Mitchell, W. and Watts, M. (2008). The occupational dimensions of local labour markets in Australian cities, Built Environment, 34, 3, 291 306.

Coombes, M.G. (2002). Travel to work areas and the 2001 Census. Report to the Office for National Statistics, Centre for Urban and Regional Development Studies, University of Newcastle, United Kingdom.

Coombes, M.G. and Openshaw, S. (1982). The use and definition of travel to work areas in Great Britain: some comments, Regional studies, 16, 2, 141-149.

Coombes, M.G., Wymer, C., Charlton, M.E., Bailey, S., Stonehouse, A. and Openshaw, S. (1987). Review of travel to work areas and small-area unemployment rates, Labour Market Trends, 105, $9-12$.

Davis, W.K. and Robinson, G.W.S. (1968). The nodal structure of the Solent region, Journal of the Town Planning Institute, 54, 18-22.

ECMA (1999). ECMAScript language specification: Standard ECMA-262, ECMA.

Geertman, S., de Jong, T. and Wessels, C. (2003). Flowmap: a support tool for strategic network analysis. In Geertman S. and Stillwell, J. (eds). Planning Support Systems In Practise, Berlin: Springer Verlag.

Guiliano, G. and Narayan, D. (2003). Another look at travel patterns and urban form: The US and Great Britain, Urban Studies, 40, 11, 2295- 2312.

Green, N. (2008) City States and the Spatial In-between. Town and Country Planning, 224-231.

Haggett, P., Cliff, A. and Frey, A. (1977). Region building, In Haggett, P. Cliff, A and Frey, A., Locational Analysis in Human Geography $\left(2^{\text {nd }}\right.$ Ed.) Volume 2: Locational Methods, Ch. 14, 486 488.

Hugo G., Champion A., Lattes A. (2003) Toward a New Conceptualization of Settlements for Demography. Population and Development Review, 29, 2, 277-297.

Morrison P.S. (1994). Work and residence in Urban Labour Markets. In Morrison P.S. (ed) Labour, 
Employment and Work in New Zealand. Proceedings of the Sixth Conference, VUW, Wellington: 249-264.

Nechyba T. J. Walsh R. P. (2004). Urban Sprawl. The Journal of Economic Perspectives, 18, 4 177-200.

Newell J.O. and Papps K L. (2001) Identifying Functional Labour Market Areas in New Zealand: A Reconnaissance Study using Travel-to-Work Data. New Zealand Department of Labour, Occasional Paper 2001/6.

Newell J.O. and Perry M. (2003). Functional Labour markets revealed by travel to work data 1991 and 2001. Monitoring and Evaluation Research Associates, Wellington and Department of Management and Enterprise Development, Massey University (Wellington).

Nystuen, J.D. and Dacey, M.F. (1961). A graph theory interpretation of nodal regions, Regional Science Association Papers and Proceedings, 7, 29-42.

Office for National Statistics (2008). Commuterview, http://www.neighbourhood.statistics.gov.uk/disse mination/Info.do?page=analysisandguidance/analy sisarticles/CommuterView.htm

Regional Growth Forum (1999). Auckland Regional Growth Strategy: 2050 - A vision for managing growth in the Auckland region, Auckland Regional Council.

Schwanen, T., Dieleman, F.M. and Dijst, M. (2004). The impact of metropolitan structure on commute behaviour in the Netherlands: a multilevel approach, Growth and Change, 35, 3, $304-333$.

Tobler, W. (2003a). Movement mapping, Centre for Spatially Integrated Social Science, available from http://www.csiss.org/clearinghouse/FlowMapper/ MovementMapping.pdf

Tobler, W. (2003b). Experiments in migration mapping by computer, Department of Geography, University of California at Santa Barbara, available from http://www.csiss.org,clearinghouse/FlowMapper/E xpMigrMapping.pdf

Tufte, E. (1983). The visual display of quantitative information, Graphics Press.

World Wide Web Consortium (W3C) (2003). Scalable Vector Graphics (SVG) 1.1 Specification, http://www.w3.org/TR/SVG11/

World Wide Web Consortium (W3C) (2006) Extensible Markup Language (XML) 1.0 (Fourth Edition), http://www.w3.org/TR/xml

\section{Acknowledgements}

The authors would like to thank the UK Office for National Statistics for permitting us to use and adapt its CommuterView visualisation tool. Special thanks are due to Alan Smith of the ONS Data Visualisation Centre for providing guidance on the inner workings of CommuterView.

\section{Author}

Martin Ralphs

Statistics New Zealand

Statistics House

The Boulevard

Harbour Quays

PO Box 2922

Wellington 6140

Martin.Ralphs@stats.govt.nz

Rosemary Goodyear

Statistics New Zealand

Statistics House

The Boulevard

Harbour Quays

PO Box 2922

Wellington 6140

Rosemary.Goodyear@stats.govt.nz

\section{Appendices}

\section{Appendix 1: Commuting tables for territorial authorities}

These tables illustrate that, though complex, it is possible to interpret results when looking at origin/destination flows at territorial authority level. At area unit level, however, the number of cells has multiplied vastly and cannot readily be interpreted in table form

Table 1: Numbers of people who listed their workplace address in one of the Four Cities of Auckland, for selected territorial authorities, 2006 Census

\begin{tabular}{|c|c|c|c|c|c|}
\hline \multirow{2}{*}{ Usual residence } & \multicolumn{5}{|c|}{ Commuting destination (workplace address) } \\
\hline & $\begin{array}{c}\text { North Shore } \\
\text { City }\end{array}$ & Waitakere City & $\begin{array}{l}\text { Auckland } \\
\text { City }\end{array}$ & $\begin{array}{l}\text { Manukau } \\
\text { City }\end{array}$ & $\begin{array}{l}\text { Total } \\
\text { Auckland }\end{array}$ \\
\hline Far North Distnct & 38 & 12 & 108 & $\overline{42}$ & 201 \\
\hline Whangarai District & 60 & 38 & 174 & 51 & 321 \\
\hline Kaipara District & 33 & 9 & 72 & 24 & 138 \\
\hline Rodney District & 6.822 & 1,701 & 5.708 & 624 & 14.858 \\
\hline North Shore City & 58.380 & 1.905 & 28,188 & 2.604 & 81,077 \\
\hline Waitakere City & 4,329 & 31,794 & 30.980 & 3.288 & 70.371 \\
\hline Auckiand City & 7.257 & 0.186 & 140.517 & 16.020 & 169.983 \\
\hline Manukau City & 1824 & 1.047 & 40.881 & 68.210 & 109.962 \\
\hline Total ALKd TAs & 71,793 & 40,832 & 240,546 & 88.125 & 441,393 \\
\hline Papakura Distnet & 177 & 84 & 3.881 & 5.079 & 9.228 \\
\hline Frankin Distnet & 171 & 99 & 3,117 & 3.720 & 7,110 \\
\hline Thames.Coromandel Distnd & 21 & 12 & 105 & $\infty$ & 195 \\
\hline Hauraki Distnct & 15 & c & 57 & 48 & 123 \\
\hline Waikato Distinct & 30 & 21 & 261 & 234 & 546 \\
\hline Hamilton City & 75 & 24 & 345 & 128 & 573 \\
\hline Waipa Distnct & 24 & $\theta$ & 84 & 39 & 156 \\
\hline Westem Bay of Plenty Distind & 15 & 9 & 72 & 24 & 120 \\
\hline Tauranga City & 60 & 27 & 195 & 78 & 363 \\
\hline Rotorua Distnct & 27 & 15 & 81 & $3 \theta$ & 165 \\
\hline Wellinglon City & 83 & 24 & 351 & 45 & 483 \\
\hline
\end{tabular}


Table 2: Number of employed population listing a workplace address in the Wellington metropolis, 2006 Census

\begin{tabular}{|c|c|c|c|c|c|}
\hline \multirow[b]{2}{*}{ Usual Residence } & \multicolumn{5}{|c|}{ Commuting destination (workplace address) } \\
\hline & $\begin{array}{l}\text { Porina } \\
\text { City }\end{array}$ & $\begin{array}{l}\text { Upper Hutt } \\
\text { Clity }\end{array}$ & $\begin{array}{l}\text { Lower Hutt } \\
\text { Clity }\end{array}$ & $\begin{array}{c}\begin{array}{c}\text { Wellington } \\
\text { City }\end{array} \\
\end{array}$ & $\begin{array}{c}\text { Total, } \\
\text { Wellington } \\
\text { clties }\end{array}$ \\
\hline Horowhenua District & 45 & 9 & 45 & 225 & 324 \\
\hline Kaplet Coast District & 879 & 174 & 756 & 3,765 & 5.574 \\
\hline Poriva City & 7,779 & 300 & 1,449 & 8,193 & 17,721 \\
\hline Upper Hutt City & 399 & 7,317 & 4,050 & 3,990 & 15.756 \\
\hline Lower Hutt Clty & 684 & 1,485 & 24,597 & 13,521 & 40,287 \\
\hline Wellington City & 2,619 & 633 & 5,256 & 79,152 & 87,660 \\
\hline Total, Wellington cities & 11,481 & 9,735 & 35,352 & 104,856 & 161,424 \\
\hline Masterton District & 9 & 39 & 90 & 213 & 351 \\
\hline Carterton District & .c & 42 & 81 & 204 & 327 \\
\hline South Wairarapa District & 18 & 93 & 156 & 450 & 717 \\
\hline Total, North Island & 12,702 & 10,239 & 36,837 & 111,144 & 170,922 \\
\hline
\end{tabular}

Table 3: Number of employed population listing a workplace address in selected territorial authorities in the Canterbury region, 2006 Census

\begin{tabular}{|c|c|c|c|c|c|}
\hline \multirow[b]{2}{*}{ Usual residence } & \multicolumn{5}{|c|}{ Commuting destination (workplace address) } \\
\hline & $\begin{array}{l}\text { Waimakarini } \\
\text { District }\end{array}$ & $\begin{array}{c}\text { Chrisichurch } \\
\text { City }\end{array}$ & $\begin{array}{l}\text { Selwynn } \\
\text { District }\end{array}$ & $\begin{array}{c}\text { Ashburtion } \\
\text { District }\end{array}$ & $\begin{array}{l}\text { Timanu } \\
\text { Distnct }\end{array}$ \\
\hline Waimakarin District & 9.033 & 8,831 & 126 & 18 & $\overline{15}$ \\
\hline Cristchurch City & 1.413 & 146.910 & 2.436 & 228 & 78 \\
\hline Sewynn District" & 75 & 7,767 & 7.068 & 132 & 12 \\
\hline Ashburton District & 12 & 287 & 150 & 12.201 & 87 \\
\hline Imaru District & 6 & 123 & 12 & 141 & 17,160 \\
\hline
\end{tabular}

Note: These figures include all people who specified a workplace address. See Appendix 3

\section{Appendix 2: Primary linkage analysis}

Primary linkage analysis was carried out using the following procedure, following the implementation described by Haggett et al. (1977):

1. Area units were sorted into descending order of total incoming flow.

2. Area units were ranked from 1 (highest incoming flow) to $\mathrm{n}$ (lowest incoming flow).

3. If the highest outflow from an area unit was to a lower ranked area unit in the hierarchy, the source area unit was designated a Terminal Hub. Terminal hubs are the biggest centres of commuter inflow and form the highest level of a hierarchy of commuter destinations. Terminal hubs are also designated First Order (O1) hubs.

4. Hierarchical relations between source area units that were not terminal hubs were determined by the largest outgoing flow from each source to a higher order destination area unit. Each source area unit may be a satellite of another area or a hub in its own right (for example of second order or third order) that also supplies commuters to a higher order hub.

5. Second, third and lower order hubs were, by definition, satellites of a higher order hub. For example, an order 4 (O4) hub with its own collection of satellites was affiliated to a larger order $3(\mathrm{O} 2)$ hub. This, in turn, was affiliated to an order 2 hub $(\mathrm{O} 2)$ and so on.

Once hierarchical relationships are defined, Geographical Information System (GIS) merged the area units that were affiliated with each Order 1 hub to form local commuting catchment areas. The zones that result are not necessarily wholly contiguous, especially for large commuter centres, but reflect the influence of those centres for commuting.

\section{Appendix 3: Workplace address}

The 2006 Census asked people the name of their business and employer, the main activity of that employer, and whether they worked at home or worked away from home. They were only asked for their workplace address if they worked away from home. Workplace address for those working at home is coded to their usual residence address. Workplace address refers to the main job held last week, which in a small number of cases may not be the main job.

There is no non-response category for the workplace address variable because respondents who were employed but did not state a workplace address were classified as 'New Zealand not further defined'. Respondents who stated a workplace address that could not be coded were also classified as 'New Zealand not further defined'. Geographical analysis of this variable is, however, confined to people whose workplace address can be defined at specific geographical levels. This varies between areas and the more detailed the geographical level the more records are excluded from the analysis. The proportion of responses where the workplace area unit is undefined is around 21 percent on average, but varies between 7 and 57 percent. The highest levels of "workplace undefined" responses are found in rural and low income Area Units.

Figure 23: Percentage of respondents who did not provide a workplace address at Area Unit level in 2006

2006 Area Units: Workplace Undefined By Respondent

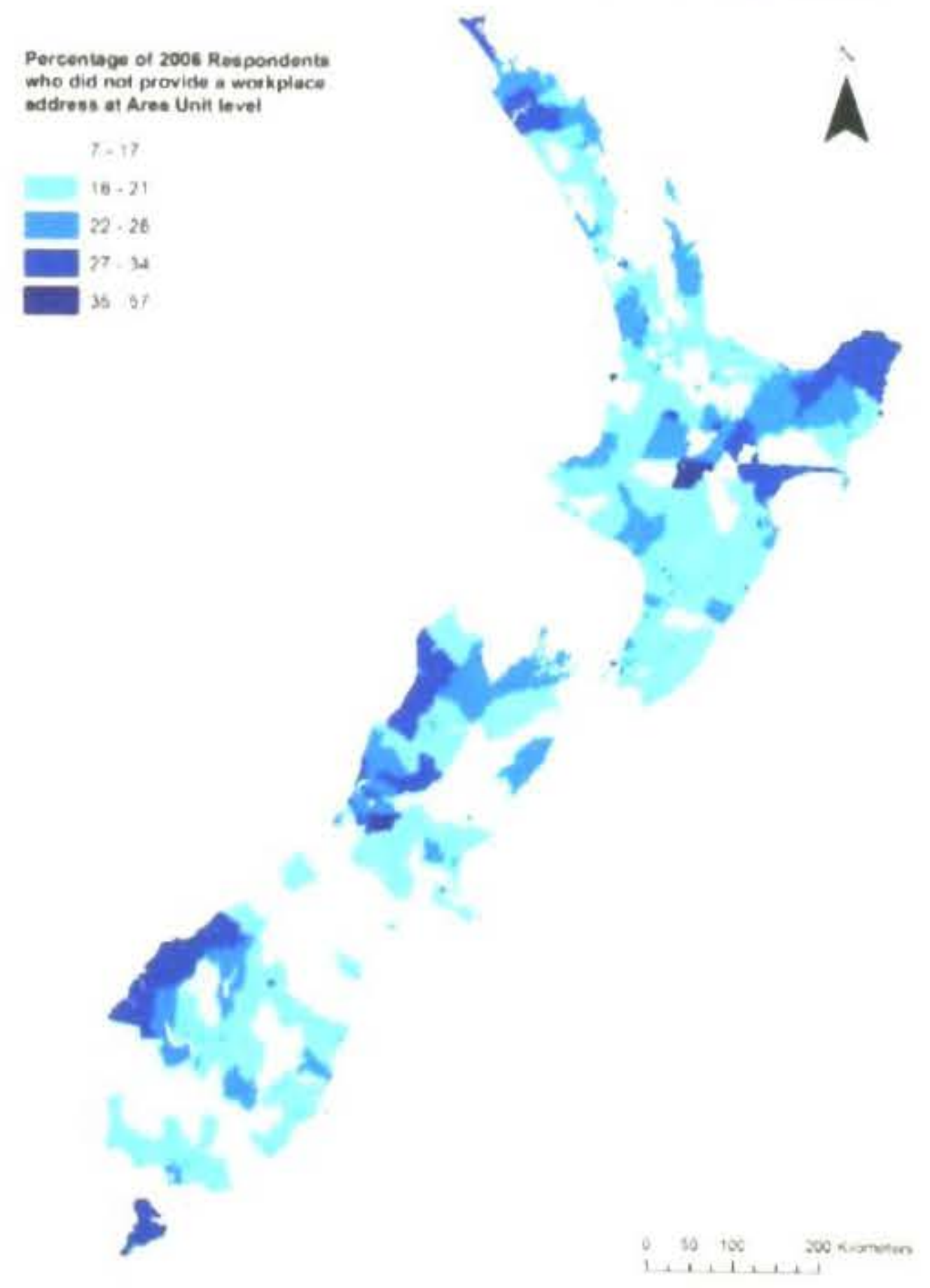


It is important to note that are two main reasons for people being included in the not defined category. In some cases people in certain occupational groups, such as builders, may have no fixed workplace. They may, for instance, explain they worked all over Auckland, so their response could be coded to regional council level but obviously not to a meshblock. In other cases people may not have given a detailed enough response or may have simply not responded to the question. Males predominated in the not defined category and tended to have not specified answers to a range of other questions such as mode of transport, occupation, and industry. However, the workplace patterns over the last censuses have been relatively consistent, which can increase our confidence in the information from people that specified their workplace address.

For more detail on the methods used in calculating workplace address see:

http://www.stats.govt.nz/statistical-

methods/classifications-and-related-statistical-

standards/workplace-address/default.htm 